\title{
EL DELITO DE ACOSO (ART. 172 TER CP) COMO MODALIDAD DE VIOLENCIA DE GÉNERO. COMPARATIVA CON EL «NACHSTELLUNG» DEL DERECHO ALEMÁN*
}

\author{
Margarita Roig Torres**
}

Resumen: La LO 1/2015, de 30 de marzo, introdujo el delito de acoso o stalking en el artículo 172 ter CP, pensando principalmente en las mujeres que sufren actos de hostigamiento por parte de sus ex parejas. El legislador siguió el modelo del delito de persecución (Nachstellung) del $\S 238 \mathrm{StGB}$, aunque este precepto ha sido recientemente reformado, dejando de ser un delito de resultado (Erfolgsdelikt) para convertirse en un delito de idoneidad (Eignungsdelikt). No obstante, la regulación española ha prescindido de la cláusula analógica del precepto alemán, evitando la infracción del principio de seguridad jurídica. En cambio, nuestros órganos judiciales han interpretado este ilícito de un modo excesivamente flexible, castigando conductas que generan mera intranquilidad, o que pueden repercutir negativamente en el ánimo de la

Recibido: mayo 2018. Aceptado: noviembre 2018

* Este artículo ha sido elaborado en el marco del Proyecto "Valoración de las recientes reformas adoptadas en los delitos de violencia de género" (AICO/2017/109), concedido por la Conselleria D’Educació, Investigació, Cultura i Esport, de la Generalitat Valenciana.

* Profesora Titular de Derecho Penal (Acred. a catedrática). ORCID ID: 0000-0003-1947-6853

Departamento de Derecho Penal. Facultad de Derecho de la Universidad de Valencia. Avda. dels Tarongers, s/n, 46022, Valencia. Email: margarita. roig@uv.es 
persona acosada. A mi juicio, el hecho de que muchas veces constituya una manifestación de la violencia de género ha llevado a relajar indebidamente las exigencias del principio de intervención mínima.

Palabras clave: acoso, stalking, violencia de género, violencia contra la mujer, Nachstellung.

\title{
THE CRIME OF STALKING (ART. 172 TER SPANISH CRIMINAL CODE) AS A MODALI OF GENDER VIOLENCE. COMPARATIVE WITH THE «NACHSTELLUNG» OF GERMAN LAW
}

\begin{abstract}
The Organic Law 1/2015, of March 30, introduced the crime of harassment or stalking in article 172 ter CP, thinking mainly of women who suffer acts of harassment by their former partners. The legislator followed the model of the crime of persecution (Nachstellung) of $\$ 238 \mathrm{StGB}$, although this precept has been recently reformed, ceasing to be a crime of result (Erfolgsdelikt) to become a crime of suitability (Eignungsdelikt). However, the Spanish regulation has dispensed with the analog clause of the German provision, avoiding the infringement of the principle of legal security. On the other hand, our judicial bodies have interpreted this illicit act in an excessively flexible way, punishing behaviors that generate mere anxiety, or that may negatively affect the mood of the harassed person. In my opinion, the fact that it often constitutes a manifestation of gender-based violence has unduly relaxed the requirements of the principle of minimal intervention.
\end{abstract}

Keywords: harassment, stalking, gender-based violence, violence against women, Nachstellung.

\section{Origen del delito de stalking}

Desde que se creó, en el Anteproyecto ${ }^{1}$ que dio lugar a la LO 1/2015, de 30 de marzo, de reforma del Código penal, el artículo 172 ter CP ha suscitado numerosas críticas por parte de la doctrina. Los aspectos cuestionados se refieren a su ubicación sistemática, la falta de precisión en la redacción del precepto, el escaso grado de lesividad de algunas conductas, la improcedente

1 Anteproyecto de Ley Orgánica por la que se modifica la Ley Orgánica 10/1995, de 23 de noviembre, del Código Penal, de 10 de octubre de 2011. 
referencia a la autorización, la infracción del principio ne bis in ídem derivada de la regla concursal, las deficiencias de los tipos agravados y la proporcionalidad de las penas. En el fondo, había recelos a que por la vía de este nuevo delito se penalicen acciones meramente molestas, que no revistan la gravedad que exige el principio de intervención mínima² ${ }^{2}$.

En realidad, la introducción de este ilícito se debe al Convenio del Consejo de Europa sobre prevención y lucha contra la violencia contra la mujer y la violencia doméstica de 2011, conocido como el Convenio de Estambul ${ }^{3}$. Esta norma prevé la obligación de los estados miembros de tipificar los comportamientos amenazadores contra otra persona cuando se realicen en varias ocasiones y le lleven a temer por su seguridad ${ }^{4}$. Sólo con carácter excepcional, en el momento de la firma las partes pueden reservarse el derecho a aplicar sanciones no penales frente a esos hechos 5 .

2 Véase, GALDEANO SANTAMARÍA, A.: “Acoso - stalking: Art. 172 ter", en ÁLVAREZ GARCÍA, F.J. (Dir.)/DOPICO GÓMEZ-ALLER, J. (Coord.): Estudio crítico sobre el anteproyecto de reforma del Código penal de 2012, Tirant lo Blanch, Valencia, 2013, p. 574; y, MATALLÍN EVANGELIO, A.: "Delito de acoso (Artículo 172 ter)", en GONZÁLEZ CUSSAC, J.L. (Dir.)/ GÓRRIZ ROYO, E./MATALLÍN EVANGELIO, A. (Coord.): Comentarios a la reforma del Código penal de 2015, $2^{\mathrm{a}}$ edición, Tirant lo Blanch, Valencia, 2015, p. 576. Lo consideran inconstitucional, BAUCELLS LLADÓS, J.: "La irreflexiva criminalización del hostigamiento en el proyecto de Código penal", en Revista General de Derecho Penal, n' 21, 2014, p. 7; y, MATALLÍN EVANGELIO, A.: “Acoso -stalking-: Art. 172 ter", en ÁLVAREZ GARCÍA, F.J. (Dir.)/DOPICO GÓMEZ-ALLER, J. (Coord.): Estudio crítico ..., cit., p. 592. Estima suficientes los tipos anteriores para subsumir las conductas hoy previstas en el artículo 172 ter CP, CARPIO BRIZ, D., en CORCOY BIDASOLO, M./MIR PUIG, S. (Dir.): Comentarios al Código penal, Tirant lo Blanch, Valencia, 2015, p. 625.

3 Ratificado por España el 27 de mayo de 2014 (BOE de 6 de junio de 2014).

4 Artículo 34. Acoso: "Las Partes adoptarán las medidas legislativas o de otro tipo necesarias para tipificar como delito el hecho, cuando se cometa intencionadamente, de adoptar, en varias ocasiones, un comportamiento amenazador contra otra persona que lleve a ésta a temer por su seguridad".

5 Artículo 78. 
Sin embargo, el Convenio define la violencia contra la mujer como una forma de discriminación, es decir, es la que sufre por razones de género y comprende las distintas formas de violencia, incluida la psicológica ${ }^{6}$.

Por otra parte, de las distintas conductas que deben penalizar los estados para evitar la violencia en el núcleo familiar y la violencia de género, el acoso se da casi exclusivamente en el ámbito de la pareja y no entre otros miembros de la convivencia doméstica. El supuesto más frecuente es el hostigamiento del hombre hacia la mujer tras la ruptura de una relación sentimental no aceptada.

Por lo tanto, el acoso se concibe como una forma de violencia de género, y con su regulación tratan de combatirse especialmente los actos de carácter amenazador del hombre a la mujer con la que ha estado unido afectivamente.

En consecuencia, este delito se ha incorporado a instancias de la Unión Europea, cuando un amplio grupo de países de nuestro entorno lo tenían ya previsto en sus legislaciones?

6 El artículo 3 del Convenio dice que, "por «violencia contra la mujer» se deberá entender una violación de los derechos humanos y una forma de discriminación contra las mujeres, y se designarán todos los actos de violencia basados en el género que implican o pueden implicar para las mujeres daños o sufrimientos de naturaleza física, sexual, psicológica o económica, incluidas las amenazas de realizar dichos actos, la coacción o la privación arbitraria de libertad, en la vida pública o privada". "Por «violencia doméstica» se entenderán todos los actos de violencia física, sexual, psicológica o económica que se producen en la familia o en el hogar o entre cónyuges o parejas de hecho antiguos o actuales, independientemente de que el autor del delito comparta o haya compartido el mismo domicilio que la víctima". "Por "género» se entenderán los papeles, comportamientos, actividades y atribuciones socialmente construidos que una sociedad concreta considera propios de mujeres o de hombres". "Por «violencia contra la mujer por razones de género» se entenderá toda violencia contra una mujer porque es una mujer o que afecte a las mujeres de manera desproporcionada".

7 Lamentaba que el legislador hubiera dejado pasar la oportunidad que le brindaba la ley de reforma de 2010 para introducir este delito, GÓMEZ RIVERO, M.C.: "El Derecho penal ante las conductas de acoso persecutorio", 
En efecto, el origen de la criminalización del fenómeno conocido como "stalking" se sitúa en los años 90 del siglo pasado en EEUU, donde fueron asesinadas varias personas famosas después de haber sido obsesivamente perseguidas por sus admiradores ${ }^{9}$, lo que provocó un gran impacto mediático, dando lugar a la aprobación de leyes anti-stalking, la primera de ellas en California en $1990^{10} \mathrm{y}$ en los tres años siguientes en los 50 estados $^{11}$ (bajo distintos nombres: stalking, criminal harassment, $\mathrm{o}$ criminal menace $)^{12}$.

Más tarde, esa normativa se generalizó, primero en el Derecho anglosajón y después en la Europa continental ${ }^{13}$. No obstante, en estos ordenamientos existen dos métodos distintos de tipificación. En algunos casos se recoge una definición amplia del delito de acoso y se precisa la idoneidad objetiva de la conducta para causar alarma o sufrimiento a la víctima, dejando a los órganos judiciales la concreción de los hechos punibles. En

en MARTÍNEZ GONZÁLEZ, M.I.: El acoso: tratamiento penal y procesal, Tirant lo Blanch, Valencia, 2011, p. 48.

8 Derivado del verbo to stalk, seguir, acechar, perseguir.

9 VILLACAMPA ESTIARTE, C.: "La introducción del delito de "atti persecutori" en el Código penal italiano", en InDret, no 3, 2009, p. 6; y, DE LA MISMA: "El proyectado delito de acecho: incriminación del stalking en Derecho penal español”, en Cuadernos de Política Criminal, n 109, 2013, pp. 10 y ss.

10 Ampliamente, VILLACAMPA ESTIARTE, C.: Stalking y Derecho penal, Iustel Madrid, 2009, pp. 23 y ss; y, DE LA MISMA: "El delito de stalking", en LAFONT NICUESA, L. (Coord.): Los delitos de acoso moral: mobbing, acoso inmobiliario, bulling, stalking, escraces y ciberacoso, Tirant lo Blanch, Valencia, 2017, p. 214.

11 ALONSO DE ESCAMILLA, A.: "El delito de stalking como nueva forma de acoso. Cyberstalking y nuevas realidades", en La Ley Penal, $\mathrm{n}^{\circ}$ 105, noviembre-diciembre, 2013, p. 2.

12 DE LA CUESTA ARZAMENDI, J.L./MAYORDOMO RODRIGO, V.: "Acoso y Derecho penal", en Eguzkilore, n 25, 2011, p. 27.

13 Sobre los motivos que pueden explicar la falta de tipificación de este delito hasta ahora en nuestro país, VILLACAMPA ESTIARTE, C.: "La respuesta jurídico-penal frente al stalking en España: presente y futuro", en ReCrim, 2010, pp. 35 y ss. 
otros, se enumeran las acciones delictivas ${ }^{14}$, aunque a veces se permite la sanción de otras análogas a las previstas.

En el artículo 172 ter CP nuestro legislador ha optado por esta técnica restrictiva, estableciendo las formas de acoso de un modo tasado. En concreto, ha tomado como modelo el delito de persecución (Nachstellung) regulado en el $§ 238 \mathrm{StGB}^{15}$, aunque ha suprimido la cláusula analógica prevista en este precepto, fijando en su lugar un catálogo cerrado de conductas típicas.

Por otra parte, el contexto actual es enteramente distinto al que dio origen a esta figura, de manera que hoy la punición del acoso no responde a la alarma creada por los medios de comunicación ${ }^{16}$, ni creo que cumpla una función puramente simbóli$\mathrm{ca}^{17}$, a la vista de los hechos que se juzgan en los tribunales. El legislador, con mayor o menor acierto, ha tratado de atajar unas situaciones excesivamente frecuentes, particularmente en casos de extinción de relaciones de pareja. No obstante, el hecho de que las acciones que integran el delito sean atípicas individualmente ha impedido precisar el injusto de una forma taxativa y ha dado lugar a una regulación que en algunos puntos es contraria a la seguridad jurídica.

Pues bien, aunque el artículo 172 ter CP recoge un delito común que no precisa cualidades específicas en los sujetos, como decía, se creó principalmente para proteger a la mujer, sobre todo en el marco de la violencia de género.

14 VILLACAMPA ESTIARTE, C.: Stalking..., cit., pp. 182 y ss.

15 Código penal alemán.

16 Apunta la importancia mediática en la creación de este delito, pero entiende que responde a la necesidad de dar una respuesta penal específica a conductas graves de persistente persecución o acoso que encontraban un difícil encaje en el Código penal, RODRÍGUEZ LAÍN, J.L.: "El nuevo delito de ciberacoso: aspectos sustantivos y procesales", en Cuadernos Digitales de Formación, nº 2, 2016, p. 2.

17 Otra opinión mantiene, BAUCELLS LLADÓS, J.: "La irreflexiva criminalización...", cit., p. 3. Considera que es una manifestación del populismo punitivo, MARTÍNEZ MUÑOZ, C.J.: "El «nuevo» delito de acoso del artículo 172 ter”, en Diario La Ley, n 9006, 22 de junio de 2017, p. 9. 
La nota de prensa publicada por el Ministerio de Justicia tras la aprobación por el Consejo de Ministros del Anteproyecto de reforma del Código penal ${ }^{18}$, anunciaba nuevas figuras delictivas, especialmente relevantes en materia de violencia sobre la mujer, como la tipificación del matrimonio forzado. Además, se castigarán los actos reiterados de acecho u hostigamiento, la divulgación no autorizada de grabaciones o imágenes íntimas obtenidas con el consentimiento de la víctima, pero luego divulgadas sin que ésta lo sepa y se incorpora al Código penal como delito la inutilización de dispositivos electrónicos usados para controlar el cumplimiento de penas.

En el «Encuentro taller sobre conclusiones extraídas de los últimos informes elaborados por el Observatorio contra la Violencia Doméstica y de Género. Buenas prácticas judiciales», organizado por el Consejo General del Poder Judicial en $2013^{19}$, se aludía al artículo 172 ter incorporado en el Anteproyecto de reforma del Código penal, como una novedad en esos campos.

Del mismo modo, tanto en la doctrina ${ }^{20}$ como en la práctica judicial ${ }^{21}$ se subraya el predomino de estas conductas en el

18 (Disponible en http://www.mjusticia.gob.es/cs/Satellite/Portal/ca/gabinetecomunicacion/noticias-ministerio/gobierno-aprueba-anteproyecto6http:// www.mjusticia.gob.es/cs/Satellite/Portal/ca/gabinete-comunicacion/noticias-ministerio/gobierno-aprueba-anteproyecto).

19 (Disponible en http://www.poderjudicial.es/cgpj/es/Temas/Violencia-domestica-y-de-genero/Actividad-del-Observatorio/Formacion/EncuentroTaller-sobre-conclusiones-extraidas-de-los-ultimos-informes-elaboradospor-el-Observatorio-contra-la-Violencia-Domestica-y-de-Genero--Buenaspracticas-judiciales---28--29-y-30-de-enero-de-2013-).

20 BUENO DE MATA, F.: "E-Violencia de género: tratamiento procesal de la violencia de género a través de la red”, en Práctica de Tribunales, $\mathrm{n}^{\circ} 101$, marzo-abril 2017, p. 103; DELGADO MARTÍN, J.: "La violencia de género en redes sociales y mediante instrumentos tecnológicos de comunicación", en Cuadernos Digitales de Formación, no 4, 2016, p. 25; GOIKOECHEA MARTÍN, L. A.: "Derecho de familia y Derecho penal. Novedades del Código penal en virtud de la Ley Orgánica $1 / 2015$ y jurisprudencia penal", en Cuadernos Digitales de Formación, no 39, 2016, p. 1; GÓMEZ RIVERO, M.C.: "El Derecho penal...", cit., p. 33; MAGRO SERVET, V.: "Reforma del Código penal afectante a la violencia de género", en Diario La Ley, ${ }^{\circ}$ 8539, 14 de mayo de 2015, p. 7; DEL MISMO: "El delito de stalking o 
contexto de la violencia de género. Por ejemplo, el AAP de Murcia 774/2017, de 21 de septiembre, apuntaba que estos hechos se repiten con frecuencia en los casos de violencia de género, y destacaba la importancia que supone su tipificación, puesto que antes las afectadas no podían ni siquiera pedir una orden de alejamiento al no estar tipificados. Igualmente, la SAP de Ceuta 14/2017, de 14 de marzo, señalaba como escenario común del stalking la ruptura de la relación de pareja y afirmaba que, a diferencia de las coacciones tradicionales, donde el sujeto conoce y quiere impedir u obligar a realizar una conducta, aquí el autor no pretende que la víctima modifique su conducta vital, todo lo contrario, busca su acercamiento y, por tanto, obtener una cierta relación con ella ${ }^{22}$.

Asimismo, diversos estudios empíricos realizados en EEUU y en Europa revelan que estos comportamientos los protagonizan mayoritariamente hombres y los padecen mujeres, en un porcentaje muy elevado por parte de sus ex parejas ${ }^{23}$.

De hecho, el Pleno del Congreso de los Diputados en su sesión del 15 de noviembre de 2016, acordó instar al Gobierno a promover un Pacto de Estado en materia de Violencia de Género y a adoptar una serie de medidas, entre ellas, "ampliar las disposiciones preventivas, procesales, punitivas y protectoras de la Ley de 2004 así como del resto del ordenamiento jurídico

acoso en la violencia de género en la reforma del Código penal", en Cuadernos Digitales de Formación, n $^{\circ}$ 56, 2016, p. 6; PALMA HERRERA en MORILLAS CUEVA, L. (Dir.): Estudios sobre el Código penal reformado, Dykinson, Madrid, 2015, p. 405; PERAMATO MARTÍN, T.: "Los nuevos tipos penales de violencia de género", en Cuadernos Digitales de Formación, $\mathrm{n}^{\circ}$ 18, 2017, p. 1; QUERALT JIMÉNEZ, J.J.: Derecho penal español. Parte especial, $7^{\text {a }}$ edición, Tirant lo Blanch, Valencia, 2015, p. 189; VILLACAMPA ESTIARTE, C. "El proyectado delito de acecho...", cit., p. 7; y, DE LA MISMA: "El delito de stalking", cit., p. 238.

21 Véase, por ejemplo, la SAP de Madrid 439/2017, de 30 de junio (F.J.5), la SAP de Madrid 491/2017, de 25 de julio (F.J.6), y el AAP de Murcia 774/2017, de 21 de septiembre (F.J.3).

22 Esta es una característica común de los delitos de violencia de género. Extensamente, BRAGE CENDÁN, S.B.: "La violencia machista: análisis del conflicto”, en Estudios Penales y Criminológicos, vol. XXXII, 2012, pp. 12 y ss.

23 Ampliamente, VILLACAMPA ESTIARTE, C.: Stalking..., cit., pp. 68 y ss. 
para abarcar, con las adaptaciones necesarias, todas las formas de violencia contra las mujeres, como el «sexting» o los nuevos tipos de acoso, hostigamiento, acecho o «stalking»" ${ }^{24}$. El Pacto de Estado fue ratificado por el Congreso el 28 de diciembre de 2017, y en la Propuesta 84 establece como objetivo "ampliar el concepto de violencia de género a todos los tipos de violencia contra las mujeres contenidos en el Convenio de Estambul", incluyendo, por tanto, el delito de acoso. Para ello, se aprobarán leyes específicas que complementarán a la LO 1/2004, de 28 de diciembre, de protección integral frente a la violencia de género, con el fin de extender las medidas de esta ley a esos hechos delictivos $^{25}$. No obstante, en el orden penal la protección frente al acoso se ha plasmado ya en el artículo 172 ter.

Por consiguiente, aunque es un delito común está enfocado especialmente a proteger a las mujeres y, a mi juicio, esta circunstancia ha influido en la interpretación judicial del artículo 172 ter $\mathrm{CP}$, sancionando hechos meramente molestos, o como dicen algunos órganos judiciales, que producen inquietud, intranquilidad o desasosiego.

\section{Contraste con el modelo alemán: delito de resultado vs delito de idoneidad}

El artículo 172 ter, apartado $1 \mathrm{CP}$, requiere que la conducta realizada sobre la persona acosada, "altere gravemente el

24 Véase, el Acuerdo de la Comisión de Igualdad, relativo al Informe de la Subcomisión para un Pacto de Estado en materia de Violencia de Género, aprobado en su reunión del 28 de julio de 2017, publicado en el Boletín General de las Cortes Generales. Congreso de los Diputados, de 8 de agosto de 2017 (Disponible en http://www.congreso.es/public_oficiales/L12/CONG/ BOCG/D/BOCG-12-D-200.PDF).

25 Extensamente, ACALE SÁNCHEZ, M.: "Aspectos penales del Pacto de Estado español contra la violencia de género de 2017", en Diritto Penale Contemporaneo, 1/2018, pp. 5 y ss. (Disponible en https://www.penalecontemporaneo.it/d/5789-aspectos-penales-del-pacto-de-estado-espaolcontra-la-violencia-de-genero-de-2017). 
desarrollo de su vida cotidiana", configurando el tipo como un delito de resultado ${ }^{26}$.

Como antes decía, esta norma es una transcripción, con algunas diferencias, del $\S 238 \mathrm{StGB}$, que regula el delito de persecución (Nachstellung) en Alemania desde el año $2007^{27}$.

El Nachstellung era hasta fecha reciente un delito de resultado, que precisaba la producción de un "deterioro grave en el estilo de vida" (schwerwiegenden Beeinträchtigung der Lebensgestaltung) de la persona perseguida. A partir de esta cláusula, en la jurisprudencia se exigía que el acecho provocase alteraciones importantes en el comportamiento externo de la víctima, que fueran más allá de los cambios normales y revistiesen carácter sustancial desde un punto de vista objetivo ${ }^{28}$. Como ejemplos de

26 CUERDA ARNAU, M.L., en GONZÁLEZ CUSSAC, J.L. (Coord.): Derecho penal. Parte especial, $5^{\text {a }}$ edición, Tirant lo Blanch, Valencia, 2016, p. 175; DE LA CUESTA ARZAMENDI, J.L./MAYORDOMO RODRIGO, V.: "Acoso...", cit., p. 45; MATALLÍN EVANGELIO, A.: "Delito de acoso...”, cit., p. 579; PALMA HERRERA en MORILLAS CUEVA, L. (Dir.): Estudios..., cit., p. 406; VILLACAMPA ESTIARTE, C.: "Delito de acecho/ stalking: art. 172 ter”, en ÁLVAREZ GARCÍA, F.J. (Dir.)/DOPICO GÓMEZ-ALLER, J. (Coord.): Estudio crítico..., cit., p. 606; DE LA MISMA en QUINTERO OLIVARES, G. (Dir.)/MORALES PRATS, F. (Coord.): Comentarios al Código penal español, Tomo I, Aranzadi, Pamplona, 2016, p. 1182; y, DE LA MISMA: "El delito de stalking”, cit., p. 236. También lo califican como un delito de resultado las siguientes resoluciones: SAP de Ceuta 14/2017, de 14 de marzo (F.J.3), SAP de Pontevedra 66/2017, de 31 de marzo (F.J.1), STS -Sala $2^{\text {a }}$ en Pleno- 324/2017, de 8 de mayo (F.J.4), SAP de Burgos 170/2017, de 26 de mayo (F.J.2), SAP de Madrid 344/2017, de 20 de junio (F.J.4), STS 554/2017, de 12 de julio (F.J.4), y SAP de Alicante, 334/2017, de 12 de septiembre (F.J.1). En cambio, considera que no constituye un elemento del tipo como tal, MAGRO SERVET, V.: "El delito de stalking..., cit., p. 10.

27 Fue introducido por Gesetz zur Strafbarkeit beharrlicher Nachstellungen (40. StrÄndG) vom 22. März 2007, Bundesgesetzblatt Teil I 2007 Nummer 11 vom 30. März 2007 Seite 354-355. (Disponible en https://dejure.org/ BGB1/2007/BGBl._I_S._354).

28 Sentencia del Tribunal Supremo alemán de 19 de noviembre de 2009 (BGH 3 StR 244/09). (Disponible en https://www.hrr-strafrecht.de/hrr/3/09/3-24409.php), Sentencia del Tribunal Supremo alemán de 19 de diciembre de 
estas modificaciones se citaban hechos como, cambiar de domicilio, o de centro de trabajo, tomar precauciones especiales al salir de casa o de noche, o renunciar a las actividades de ocio ${ }^{29}$. En consecuencia, la presión psíquica y los perjuicios psicológicos no eran suficientes para estimar producido el resultado.

Sin embargo, esta exigencia fue censurada tanto por la doctrina $^{30}$ como por la jurisprudencia ${ }^{31}$, en la medida en que se supeditaba el castigo a la reacción de la parte agraviada, en lugar de cifrar el injusto en la gravedad y la lesividad de la conducta del autor.

Pues bien, la Ley de mejora de la protección contra la persecución (Gesetz zur Verbesserung des Schutzes gegen Nachstellungen) de 1 de marzo de $2017^{32}$, reformó el tipo básico regulado en el apartado 1 del $\S 238 \mathrm{StGB}$, que ha dejado de ser un delito de resultado (Erfolgsdelikt) y se ha convertido en un delito de idoneidad (Eignungsdelikt). Ya no se requiere que la persona acechada efectivamente haya realizado modificaciones trascendentes en su actividad cotidiana, sino que basta que la conducta del autor sea adecuada para provocar esos cambios.

2012 (BGH 4 StR 417/12). (Disponible en https://www.hrr-strafrecht.de/ hrr/4/12/4-417-12.php?referer=db), y, Sentencia del Tribunal Supremo alemán de 16 de junio de 2014 (BGH 4 StR 111/14). (Disponible en https:// www.hrr-strafrecht.de/hrr/4/14/4-111-14.php?referer=db).

29 Sentencia del Tribunal Supremo alemán de 19 de noviembre de 2009 (BGH 3 StR 244/09). (Disponible en https://www.hrr-strafrecht.de/hrr/3/09/3-24409.php), y, Sentencia del Tribunal Supremo alemán de 19 de diciembre de 2012 (BGH 4 StR 417/12). (Disponible en https://www.hrr-strafrecht.de/ hrr/4/12/4-417-12.php?referer=db).

30 MÜLLER, H.E.: "Reform des $\S 238$ StGB - "Stalking”, eine gute Idee?", beck-community, de 17 de febrero de 2016. (Disponible en https://community.beck.de/2016/02/17/reform-des-238-stgb-stalking-eine-gute-idee).

31 Sentencia del Tribunal Supremo alemán de 19 de noviembre de 2009 (BGH 3 StR 244/09). (Disponible en https://www.hrr-strafrecht.de/hrr/3/09/3-24409.php).

32 Gesetz zur Verbesserung des Schutzes gegen Nachstellungen vom 1. März 2017, Bundesgesetzlbatt Teil I 2017 Nummer 11 vom 9. März 2017. Seite 386-387). (Disponible en https://dejure.org/BGBl/2017/BGB1._I_S._386). 
Por lo tanto, el núcleo del tipo reside en el comportamiento del sujeto activo y no en la respuesta de quien lo sufre.

Como apuntaba el Gobierno en el Proyecto de ley, antes la protección penal sólo existía si la víctima variaba su rutina y sucumbía a la presión del ofensor. Por consiguiente, la responsabilidad penal no dependía de las acciones del infractor ni de su calidad, sino únicamente de cómo reaccionaba la persona aco$\operatorname{sada}^{33}$. En definitiva, la reforma perseguía mejorar la protección frente al stalking $y$ facilitar la condena de sus autores ${ }^{34}$.

En cambio, en España sigue siendo un delito de resultado. El artículo 172 ter CP fue introducido por la LO 1/2015, de 30 de marzo, cuando todavía no se había publicado el Proyecto de reforma alemán de 12 de octubre de 2016, lo que explica que la redacción de este elemento coincida en lo esencial con la versión original del $\S 238 \mathrm{StGB}$.

Ahora bien, a diferencia del Derecho germánico, en nuestro sistema no se ha precisado con suficiente nitidez cuándo existe una alteración grave de la vida cotidiana, y en concreto si el resultado implica una modificación de las pautas de actuación externas o si concurre también cuando se produce una perturbación psicológica seria. En este punto las resoluciones judiciales son discordantes.

En algunas sentencias se niega la aplicación del artículo 172 ter CP por no haberse acreditado que el acusado haya ocasionado el resultado típico ${ }^{35}$. Desde esta perspectiva, se enumeran ejemplos, que entrañan una modificación de las pautas externas: cambiar de cerradura, dejar de ir por el itinerario habitual de casa al trabajo, renunciar a zonas de ocio, cambiar de residencia o domicilio, de número de teléfono o simplemente dejar de salir

33 (Disponible en http://dip21.bundestag.de/dip21/btd/18/099/1809946.pdf).

34 Declaraciones del Ministro Heiko Maas. (Disponibles en http://www.bmjv. de/SharedDocs/Pressemitteilungen/DE/2016/07132016_Kabinett_Schutz_ Stalking.html).

35 SAP de Teruel 532/2017, de 4 de octubre (F.J.4). 
de casa para relacionarse ${ }^{36}$; variar los hábitos, horarios, lugares de paso, números de teléfono, cuentas de correo electrónico, o de vivienda y trabajo ${ }^{37}$.

Sin embargo, generalmente esa alteración grave de la vida cotidiana se interpreta como necesidad de que la víctima haya sufrido temor, perturbación o inquietud ${ }^{38}$. Incluso, en algunas resoluciones se precisa simplemente la adecuación del acoso para producir estos efectos.

En este sentido, se afirma, por ejemplo, que la comunicación o aproximación asfixiante y no querida ha de ser "susceptible de generar algún tipo de repercusión en la víctima, que mayoritariamente se identifica con la producción de desasosiego o temor" ${ }^{39}$, o más claramente, que "se requiere un resultado de perturbación o inquietud" 40 . En esta misma dirección, se argumenta que "la afectación grave del desarrollo de la vida cotidiana de la víctima, puede manifestarse de muchas maneras cumpliéndose, más allá de manifestaciones concretas, cuando se sume a la víctima en un estado de ansiedad que menoscaba o destruye su tranquilidad y seguridad"41.

En otros casos, se pone el acento en la perseverancia del autor ${ }^{42}$, o en la vocación de sistematizar la conducta, como

36 SAP de Lugo 122/2017, de 28 de junio (F.J.2)

37 SAP de Madrid 491/2017, de 25 de julio (F.J.6).

38 De esta opinión, RODRÍGUEZ LAIIN, J.L.: "El nuevo delito de ciberacoso...", cit., p. 5; y, VELASCO NÚÑEZ, E.: "Los delitos informáticos", en Cuadernos Digitales de Formación, n 33, 2015, p. 20.

39 SAP de Madrid 745/2017, de 28 de septiembre (F.J.3).

40 SAP de Madrid 344/2017, de 20 de junio (F.J.4).

41 SJ Instrucción de Tudela de 23 de marzo de 2016 (F.J.1), y SAP de Pontevedra 66/2017, de 31 de marzo (F.J.1).

42 "Se exige implícitamente una cierta prolongación en el tiempo; o, al menos, que quede patente, que sea apreciable, esa voluntad de perseverar en esas acciones intrusivas, que no se perciban como algo puramente episódico o coyuntural, pues en ese caso no serían idóneas para alterar las costumbres cotidianas de la víctima". SAP de Pontevedra 576/2017, de 8 de septiembre (F.J.4). 
presupuestos de la idoneidad de la actuación para modificar los hábitos, costumbres, rutinas o forma de vida de la víctima, pero $\sin$ requerir su alteración real ${ }^{43}$. Incluso se apunta que debe valorarse si el comportamiento, por sus características, reiteración y prolongación en el tiempo, es adecuado para llegar a afectar seriamente al equilibrio psíquico de la persona afectada y desembocar en la adopción de cambios sustanciales en la forma de conducirse o relacionarse socialmente en su vida diaria. Es decir, se analiza la capacidad de los actos de hostigamiento para producir una presión psicológica seria en quien los sufre $e^{44}$.

Desde ese mismo enfoque flexible, en ocasiones se identifica el resultado con una limitación de la capacidad de decidir o de actuar ${ }^{45}$, lo que en principio no conlleva necesariamente consecuencias en la forma de vida externa, pues es posible que pese a sentirse presionada la persona acosada decida no variar sus rutinas.

El Tribunal Supremo, en la sentencia 324/2017, de 8 de mayo, adoptada por la Sala $2^{\mathrm{a}}$ en Pleno, declaraba lo siguiente:

"Globalmente considerada no se aprecia en esa secuencia de conductas, enmarcada en una semana, la idoneidad para obligar a la víctima a modificar su forma de vida acorralada por un acoso sistemático sin visos de cesar..., la proximidad temporal entre los dos grupos de episodios; la calma durante

43 "De estos mensajes no se desprende una vocación de persistencia o una intencionalidad, latente o explícita, de sistematizar o enraizar una conducta inclusiva sistemática (persecución, reiteración de llamadas...) capaz de perturbar los hábitos, costumbres, rutinas o forma de vida de la víctima ni que puedan ser considerados idóneos o con capacidad para alterar gravemente la vida ordinaria de esta". SAP de Madrid 556/2017, de 11 de octubre (F.J.2).

44 SAP de Burgos 170/2017, de 26 de mayo (F.J.2).

45 "Por tanto, se está ante un delito de resultado en la medida en que se exige que las referidas conductas causen directamente una limitación trascendente en alguno de los aspectos integrantes de la libertad de obrar del sujeto pasivo, ya sea en la capacidad de decidir, ya en la capacidad de actuar según lo ya decidido. En definitiva, y como ya se ha dicho, que causen una alteración grave de su vida cotidiana". STS 554/2017, de 12 de julio (F.J.4). 
el periodo intermedio; así como la diversidad tipológica y de circunstancias de las conductas acosadoras impiden estimar producido el resultado, un tanto vaporoso pero exigible, que reclama el tipo penal: alteración grave de la vida cotidiana (que podría cristalizar, por ejemplo, en la necesidad de cambiar de teléfono, o modificar rutas, rutinas o lugares de ocio...). No hay datos en el supuesto presente para entender presente la voluntad de imponer un patrón de conducta sistemático de acoso con vocación de cierta perpetuación temporal. El tipo no exige planificación, pero sí una metódica secuencia de acciones que obligan a la víctima, como única vía de escapatoria, a variar sus hábitos cotidianos. Para valorar esa idoneidad de la acción secuenciada para alterar los hábitos cotidianos de la víctima hay que atender al estándar del "hombre medio", aunque matizado por las circunstancias concretas de la victima (vulnerabilidad, fragilidad psíquica, ...) que no pueden ser totalmente orilladas".

Por lo tanto, el Tribunal requiere la aptitud de la actividad hostigadora para obligar a la víctima a modificar sus hábitos cotidianos. Para calibrar esa virtualidad se ha de estar al estándar de un "hombre medio", aunque tomando en consideración las circunstancias particulares de la persona acechada. De forma que precisa únicamente la adecuación del acoso para provocar el resultado típico, que interpreta en sentido objetivo como alteración de las pautas de actuación. En el fondo, pues, coincide con la mayoría de las resoluciones anteriores, puesto que los actos del autor tienen que ser idóneos para influir psicológicamente en la parte agraviada y hacerle introducir cambios en su estilo de vida, aunque no es necesario que estas modificaciones se produzcan.

Esta línea interpretativa, que se centra en la presión psíquica ejercida sobre la persona acosada responde, como indican muchas de esas resoluciones, al bien jurídico protegido, que según expresa el propio legislador en la Exposición de Motivos de la LO 1/2015, de 30 de marzo, es la libertad y el sentimiento de seguridad de la víctima. Ahora bien, este objeto de tutela no 
impide entender el resultado típico de un modo más restrictivo ${ }^{46}$, precisando la modificación del comportamiento externo como se hace en Alemania, donde se estima que el $\S 238$ StGB protege la libertad de decisión y de actuación ${ }^{47}$. De hecho, creo que el tenor literal de la citada cláusula del artículo 172 ter CP ("altere gravemente el desarrollo de su vida cotidiana"), implica esta exigencia de un cambio importante en las actuaciones habituales.

Sin embargo, a mi juicio, este resultado típico es contrario al principio de certeza ${ }^{48}$, puesto que el infractor desconoce de antemano las consecuencias de sus actos, como se desprende de las resoluciones anteriores, que lo entienden de forma distinta. Por otra parte, vulnera el principio de proporcionalidad, en tanto la punición se condiciona a la reacción de la víctima, de manera que una conducta puede ser castigada y otra semejante o incluso más grave resultar impune, según la persona acosada tome medidas o no ante el hostigamiento. Además, esta respuesta suele depender de la clase de actos de acoso perpetrados por el infractor. Si se producen por medios de telecomunicación, será frecuente que la parte afectada bloquee el contacto del acosador en el whatssap, que cambie de número de teléfono o de cuen-

46 Requiere una modificación en los hábitos de vida, MARTÍNEZ MUÑOZ, C.J.: "El «nuevo» delito de acoso...", cit., p. 2.

47 EISELE, J., en SCHÖNKE, A./SCHRÖDER, H.: Strafgesetzbuch: Kommentar, 29 Auflage, C.H.Beck, München, 2014, pp. 1579 y 1580; KUBICIEL, M./BORUTTA, N.: "Strafgrund und Ausgestaltung des Tatbestandes der Nachstellung", en KriPoZ, no 3, 2016, pp. 194 y ss; y, MEYER, F.: "Strafbarkeit und Strafwürdigkeit von «Stalking» im deutschen Recht", en $Z S t W, \mathrm{n}^{\circ} 115,2003$, pp. 1579 y 1580.

48 Puede verse una crítica a esta cláusula en, LAMARCA PÉREZ, C., en LAMARCA PÉREZ, C (Coord.): Delitos. La parte especial del Derecho penal, Dykinson, Madrid, 2017, p. 142; PALMA HERRERA en MORILLAS CUEVA, L. (Dir.): Estudios..., cit., p. 406; PUJOLS PÉREZ, S.: “Aplicación del delito de quebrantamiento de condena como respuesta penal a las conductas de stalking: problemática suscitada", en Revista General de Derecho Penal, no 23, 2015, p. 25; QUERAL JIMÉNEZ, J.J.: Derecho penal español. Parte especial, $7^{\mathrm{a}}$ edición, Tirant lo Blanch, Valencia, 2015, p. 177; y, VILLACAMPA ESTIARTE, C.: "Delito de acecho/stalking...", cit., p. 606 . 
ta de Facebook. Pero si consisten en un acercamiento personal, mediante visitas al puesto de trabajo o al domicilio, la decisión de abandonarlos es mucho más drástica y en ella intervienen diversos factores, profesionales, económicos, familiares, etc. En este caso requerir una modificación de esta clase para condenar al responsable me parece desproporcionado en comparación con otras situaciones de hostigamiento.

Los órganos judiciales españoles han realizado, en términos generales, una interpretación del delito de acoso próxima a la que se ha plasmado en el $\S 238$ StGB tras la reforma de 2017. De modo que, aunque el tipo del artículo 172 ter CP mantiene su naturaleza de delito de resultado, en la práctica se atiende a la idoneidad del hostigamiento para provocar cambios en las rutinas esenciales de la víctima. Para valorar esa capacidad el Tribunal Supremo fija como canon la respuesta que cabe esperar de un hombre medio, complementada con las características de la concreta persona acosada. Pero esta lectura no se deriva claramente de la ley, lo que explica que haya sentencias que mantienen otras posturas más laxas, requiriendo tan solo que los actos sean apropiados para intranquilizar a quien los sufre.

Desde mi punto de vista, por tanto, el legislador español debería reformar el artículo 172 ter, apartado $1 \mathrm{CP}$, para exigir, al igual que en el ordenamiento alemán solamente la adecuación objetiva de los actos de acoso para afectar gravemente al desarrollo de la vida de la víctima.

Ahora bien, la diferente interpretación efectuada por los tribunales alemanes y españoles evidencia que la exigencia de un cambio en las circunstancias externas, frente a la pura constatación de una perturbación psíquica o de la aptitud de la actuación para producirla, ha determinado que los supuestos condenados en Alemania revistan, en general, una mayor gravedad que los sancionados en nuestra práctica judicial. Por eso, es fundamental insistir en que lo determinante para aplicar este delito de acoso no es el resultado, que se debe suprimir en atención a los principios de seguridad jurídica y de proporcionalidad, sino 
la entidad de la conducta. De modo que sólo deben castigarse los comportamientos que afecten seriamente a la libertad de la víctima y no los que generen mera intranquilidad o inquietud.

Por ejemplo, en Alemania se negó la aplicación del § 238 StGB a un acusado que realizó una cantidad considerable de llamadas a su ex pareja, le dejó multitud de mensajes telefónicos y llamó también a su puesto de trabajo. La mujer cambió su número de teléfono, abandonó su casa y alquiló una habitación durante una semana, y dejó de utilizar un apartamento, salvo cuando iba acompañada, además de sufrir insomnio a raíz de esos hechos ${ }^{49}$.

Igualmente, se estimó que no se habían acreditado cambios sustanciales en la forma de vida externa que permitieran apreciar el delito de persecución, pese a que en los hechos probados de la sentencia impugnada se recogían múltiples actos de acecho (seguimiento con el coche, envío masivo de cartas, visitas al lugar de trabajo y al domicilio... $)^{50}$ y perjuicios

49 Sentencia del Juzgado de instrucción (AG) de Löbau de 17 de abril de 2008 (5 Ds 440 Js 1612/07, StV 2008, 646). KRÜGER, M.: "Stalking in allen Instanzen - Kritische Bestandsaufnahme erster Entscheidungen zu $\S 238$ StGB", en $N S t Z, \mathrm{n}^{\circ} 10,2010$, p. 546.

50 “a) Período del 20 de mayo de 2009 al 3 de marzo de 2011. En diversos días, el acusado estacionó su automóvil cerca de la casa de la víctima y la observó. Un día, cuando ella se dirigía al banco, la siguió con su coche durante aproximadamente una hora, mirándola repetidamente, de forma opresiva. El acusado arrojó al menos 22 cartas en el buzón de la víctima, expresando de modo confuso con alguna amenaza mortal, que ambos estaban destinados a estar juntos y ella tenía que someterse a su voluntad. Mediante una orden de 28 de octubre de 2010, el Tribunal... prohibió al acusado..., acercarse a menos de doscientos metros a la mujer, su hogar y su lugar de trabajo. El acusado entendió la solicitud de una orden de prohibición de aproximación como un acto de rechazo hacia él... A partir de ese momento estuvo casi siempre presente. Entre otras cosas, esperó junto a su vivienda, cuando regresó de un viaje de negocios. Con motivo de un paseo en bicicleta por una ruta solitaria, el acusado de modo repentino e inesperado se interpuso en su camino. A partir de febrero de 2011, también comenzó a visitar su lugar de trabajo, escribió una carta a su empleador y observó durante horas cómo trabajaba. 
psicológicos serios, que requirieron de tratamiento farmacológico. Además, constaban modificaciones de las circunstancias externas, con varias bajas laborales y adopción de medidas de control frente al acosador ${ }^{51}$.

Estas sentencias contrastan con algunas recaídas en la práctica judicial española, en las que se condena pese a no recogerse ninguna alteración en las rutinas de la víctima.

Así, se anuló el auto de archivo de una causa en la que consta que la denunciante había recibido numerosas llamadas telefónicas y requerimientos de pago de una deuda inexistente, pero no se recoge ningún efecto de estos actos, ni de carácter psicológico ni un cambio de hábitos por parte de la destinataria,

b) Período del 11 de agosto de 2011 al 27 de noviembre de 2011. Debido a una infracción de la medida cautelar de alejamiento, el acusado fue detenido y encarcelado... Después de salir en libertad, intensificó su acercamiento a la víctima. Ésta recibió casi diariamente cartas del acusado, cuyo contenido se volvió cada vez más extraño. El 15 de agosto de 2011, él la persiguió cuando visitó a un amigo. El 16 y 18 de agosto de 2011, estuvo claramente visible en frente de su edificio de apartamentos y el 24 de agosto 2011 permaneció en los locales de la empresa. Junto a las cartas del 31 de agosto y de 4 de septiembre de 2011 le envió como obsequios un reloj de cuarzo para mujer y tres $\mathrm{CD}$ de música.

El 10 de septiembre de 2011, el acusado regresó a la casa de la víctima, que lo comunicó a la policía.... El 21 de septiembre de 2011, los oficiales de policía..., se reunieron con él cuando introducía una nueva carta en el buzón de la casa de la demandante...". Sentencia del Tribunal Supremo alemán de 19 de diciembre de 2012 (BGH 4 StR 417/12). (Disponible en https://www. hrr-strafrecht.de/hrr/4/12/4-417-12.php?referer=db).

51 "Como consecuencia de estos hechos, el Tribunal regional ha declarado que la mujer se ve psicológica y físicamente afectada de modo significativo por las acciones del acusado (trastornos del sueño, ataques de pánico, inquietud, dificultad para respirar, problemas gastrointestinales graves, tinnitus). Ha tomado antidepresivos... En ocasiones, debido a su estado de salud, ya no pudo continuar con su actividad profesional y en tres ocasiones estuvo incapacitada durante varios días. Antes de regresar a casa por la noche, preguntaba por teléfono a los vecinos si el acusado estaba al acecho en su automóvil cerca del apartamento. Ante el temor al acusado, ya no podía andar sola ni salir en bicicleta. Ha perdido la confianza esencial de estar a salvo cuando se va de casa". 
quien no obstante sí indicó en la denuncia que los hechos habían afectado a su salud psíquica ${ }^{52}$.

De igual modo, se desestimó el recurso interpuesto por el condenado por un delito del artículo 172 ter $\mathrm{CP}$, en el que alegaba que la propia denunciante, su ex esposa reconoció no tenerle miedo y no se produjo una alteración grave en el desarrollo de su vida cotidiana. La condena se basa en los hechos de hostigamiento, consistentes en el envío de numerosos mensajes de whatsapp, llamadas telefónicas y frases humillantes ${ }^{53}$.

Asimismo, se consideró constitutivo del delito de acoso el envío por parte del autor a su ex pareja de cientos de mensajes de móvil. Dice el tribunal que estos hechos objetivamente valorados y analizados en su conjunto integran el tipo del artículo 172 ter $\mathrm{CP}$, y añade que esta conducta, además, se ha visto acompañada de expresiones susceptibles de incidir negativamente en el ánimo de la destinataria. Concluye que esas comunicaciones crearon en la víctima una grave alteración en su desarrollo vital, pero sin especificar datos concretos, por lo que parece referirse a la influencia psíquica que presupone en este tipo de $\operatorname{actos}^{54}$.

52 "En la denuncia que dio lugar a la incoación de las presentes Diligencias previas se refería que la denunciante ha venido siendo acosada por parte de personas que llaman continuamente a su domicilio y mandan requerimientos en nombre de L.H.S., reclamando la devolución de un préstamo de 7.836,91 euros. Las llamadas se efectúan desde diferentes números de teléfono para evitar identificar la llamada y así evitar no contestarla, a distintas horas del día, hasta dos veces por día en ocasiones, así como los requerimientos mediante cartas, habiendo llegado a amenazar a la denunciante con que, si le reclaman judicialmente la cantidad que adeuda, tendrá que pagar costas en un 30 por 100 , cuando en realidad la declarante no ha suscrito préstamo alguno con esa entidad. Igualmente se señalaba en la denuncia que la denunciante se ha dirigido a L.H.S a través de sus abogados a la empresa en cuyo nombre se vienen realizando tales requerimientos, telefónicos y por correo, para negarle su carácter de interlocutora en la gestión extrajudicial del cobro del crédito, si es que hubiera alguna suma exigible; y en segundo lugar, al persistir las llamadas de forma incesante, se han dirigido a la acreedora para instarle a que ejercite de una vez la reclamación judicial correspondiente". SAP de León 1101/2017, de 20 de octubre (F.J.1).

53 SAP de Teruel 23/2017, de 21 de junio (F.J.1).

54 SAP de Alicante 176/2017, de 10 de marzo (F.J.1). 
También se mantuvo la condena de la acusada que mandó numerosos mensajes al teléfono de su ex marido, a través de whatsapp y de mensajes de texto, sin que se exprese en la sentencia ningún cambio en el desarrollo de la vida del afectado. El tribunal argumenta que para cualquier observador imparcial, esa permanente, desordenada, dilatada, exagerada y no justificada remisión de mensajes y comunicaciones telefónicas no puede asumirse con normalidad y sin perturbación, ni obedecer a otro ánimo que el de inmiscuirse en la vida del receptor más allá de los límites tolerables, causando una intranquilidad en éste y un desasosiego objetivamente perceptible y rechazable ${ }^{55}$.

De igual forma, se recoge como fundamento de la condena por este delito que el autor, después de conocer a la denunciante, comienza a hacerle llamadas telefónicas, le envía mensajes de whatsapp escritos y de audio, así como fotografías y finalmente comienza a remitirle mensajes de contenido sexual, alterando la normal vida de la denunciante. Esta perturbación se refiere a la presión psicológica que cabe deducir de estos hechos.

En otra resolución se confirma la condena del recurrente que tras el divorcio realizó actos de acoso hacia su ex esposa. Intentó ponerse en contacto con ella de modo reiterado, creando incluso grupos de whatsapp cuando ella lo bloqueaba, le envió regalos a su lugar de trabajo y aprovechó para cenar con la familia de ella mientras ésta dormía. Se afirma en el fallo que consiguió provocar un gran temor en la acosada, viéndose afectado el desarrollo de su vida cotidiana e incluso de su actividad laboral ${ }^{56}$.

En estos casos llama la atención la escueta fundamentación relativa al resultado típico, a diferencia de la minuciosidad exigida en la jurisprudencia alemana, como se desprende de la segunda sentencia citada, donde se reproducen algunas secuencias del fallo recurrido que describen los efectos provocados en

55 SAP de Madrid 344/2017, de 20 de junio (F.J. 1 y 4).

56 SAP de Madrid 439/2017, de 30 de junio (F.J.1). 
la acosada: como consecuencia de los perjuicios psíquicos sufridos tuvo que tomar antidepresivos; a veces, debido a su estado de salud, ya no pudo continuar con su actividad profesional y en tres ocasiones estuvo incapacitada durante varios días; antes de regresar a casa por la noche, preguntaba por teléfono a los vecinos si el acusado estaba al acecho en su automóvil cerca del apartamento; ante el temor al acusado ya no podía andar sola... Pues bien, pese a que estos hechos constaban como probados, el Tribunal Supremo entendió que la condena carecía de suficiente justificación para apreciar una injerencia grave en la forma de vida. Por el contrario, en las sentencias que he apuntado recaídas en nuestro país, la condena se funda en la actividad de hostigamiento y a partir de ella se afirma el resultado, en algunos casos por estimar sencillamente que el comportamiento tiene la suficiente trascendencia como para producir una situación de intranquilidad o perturbación en la víctima, o para afectarle negativamente en su ánimo.

En consecuencia, la reforma verdaderamente necesaria en nuestro país, además de la supresión del resultado, que de facto han omitido muchos órganos judiciales, es la necesidad de limitar las condenas a las conductas graves, objetivamente adecuadas para provocar cambios importantes en la forma de vida de la víctima. Considerar como delito, castigado con una pena de prisión o multa, un comportamiento simplemente apto para producir desasosiego e intranquilidad es contrario al principio de intervención mínima.

\section{Diferencias en cuanto a los requisitos comunes}

En España el artículo 172 ter CP se ubica en el capítulo "De las coacciones", lo que, a mi juicio, resulta inadecuado teniendo en cuenta el bien jurídico que el legislador quiere proteger. Según expresa en la Exposición de Motivos de la LO $1 / 2015$, de 30 de marzo, en esa norma se sancionan conductas que menoscaban gravemente la libertad y el sentimiento de seguridad de la víctima, pero que no tienen encaje en las amenazas 
ni en las coacciones ${ }^{57}$. Por lo tanto, regularlo como una modalidad de este ilícito, en el que se protege la libertad de obrar, resulta incoherente ${ }^{58}$. Sería preferible dedicarle un capítulo independiente, dentro de los delitos contra la libertad, como se hace en Alemania, donde el $\S 238 \mathrm{StGB}^{59}$ se encuentra en el Capítulo 18, dedicado a los "Delitos contra la libertad personal". A partir de esta posición sistemática la doctrina mayoritaria entiende que el objeto de tutela es la libertad de decisión y de actuación, de modo que estas parcelas se protegen frente a conductas que no

57 Ampliamente, sobre la dificultad de sancionar las conductas de acoso en los tipos existentes, GÓMEZ RIVERO, M.C.: "El Derecho penal...", cit., pp. 38 y ss.

58 Critican esta ubicación sistemática, ALONSO DE ESCAMILLA, A.: "El delito de stalking...", cit., p. 4; GALDEANO SANTAMARÍA, A.: "Acoso...", cit., p. 569; GUTIERREZ CASTAÑEDA, A.: "Acoso - stalking: art. 173 ter”, en ÁLVAREZ GARCÍA, F.J. (Dir.)/DOPICO GÓMEZ-ALLER, J. (Coord.): Estudio critico..., cit., p. 584; y, VILLACAMPA ESTIARTE, C., en QUINTERO OLIVARES, G. (Dir.)/MORALES PRATS, F. (Coord.): Comentarios ..., cit., pp. 1178 y 1179.

$59 \S 238$ StGB. Persecución (Nachstellung).

1) "Será castigado con una pena de prisión de hasta tres años o con una multa quien persiga a otra persona, de una manera no autorizada que sea adecuada para afectar gravemente su modo de vida, en cuanto de modo persistente:

1. busca la proximidad física de esta persona,

2. intenta contactar con esta persona mediante el uso de medios de telecomunicación u otros medios de comunicación o a través de un tercero,

3. utiliza abusivamente los datos personales de esta persona para realizar pedidos de bienes o servicios a nombre de esa persona o bien provoca que algún tercero entre en contacto con ella empleando dicho mecanismo,

4. amenaza a esta persona con lesionar la vida, integridad física, salud o libertad propia o de uno de sus parientes o cualquier otra persona cercana a ellos, o

5. comete otra conducta semejante.

2) Se impondrá pena de prisión de tres meses a cinco años si el autor pone a la víctima, un pariente de la víctima u otra persona cercana a la víctima en peligro de muerte o grave daño a la salud.

3) La pena será de entre uno a diez años de prisión si el delincuente causa la muerte de la víctima, o de otra persona cercana a la víctima.

En los casos a los que se hace referencia en el párrafo 1, el delito solo se enjuiciará previa denuncia, a menos que la fiscalía considere necesario intervenir de oficio debido a especiales intereses públicos". 
conllevan el anuncio de un mal ni el uso de violencia, por lo que no son punibles mediante aquellas figuras. En cambio, en nuestro ordenamiento la alusión al sentimiento de seguridad ha determinado que diversos órganos judiciales castiguen acciones que simplemente crean una sensación de inseguridad o intranquilidad a la persona acosada. Entiendo, pues, que sería más apropiada la previsión autónoma de este ilícito y su limitación a los atentados graves contra la libertad de decidir y de actuar conforme a esa decisión.

Creo que el hecho de que afecte, sobre todo, a las mujeres y que se de en un porcentaje elevado de casos en el ámbito de la pareja o ex pareja no debe llevar a relajar las exigencias relativas a la lesividad de la conducta y el principio de intervención mínima.

En cuanto al tipo básico, el artículo 172 ter CP castiga al que acose "a una persona llevando a cabo de forma insistente y reiterada, y sin estar legítimamente autorizado", alguna de las conductas que se recogen a continuación.

En la doctrina se ha criticado el uso del verbo acosar, por incluirse en la descripción típica el propio concepto que se quiere definir y por la falta de consenso que existe en cuanto a las características de esta conducta ${ }^{60}$. Según el Diccionario de la Real Academia Española de la Lengua, acosar significa "perseguir, sin darle tregua ni reposo, a un animal o a una persona" (significado $1^{\circ}$ ), o "apremiar de forma insistente a alguien con molestias o requerimientos" (significado $3^{\circ}$ ). Posiblemente, se quisieron evitar las objeciones que en Alemania se han formulado al término persecución (Nachstellung), utilizado en el $§ 238$ $\mathrm{StGB}$, donde se ha argumentado que es apropiado en el delito de caza furtiva, del que lo tomó el legislador al tipificar el stalking,

60 BAUCELLS LLADÓS, J.: "La irreflexiva criminalización...”, cit., p. 6; y, VILLACAMPA ESTIARTE, C., en QUINTERO OLIVARES, G. (Dir.)/ MORALES PRATS, F. (Coord.): Comentarios ..., cit., p. 1180. Con carácter general para las diferentes modalidades de acoso, ponía de relieve la excesiva amplitud y ambigüedad de este término, MUÑOZ CONDE, F.: "Diversas modalidades de acoso punible en el Código penal", en MARTÍNEZ GONZÁLEZ, M.I.: El acoso..., cit., p. 18. 
pero es inadecuado para personas, porque esa acción puede ser plenamente legítima ${ }^{61}$. Desde luego, llama la atención que en algunas modalidades recientes de acoso (art. 173.1, párrafo 2 -acoso laboral-y art. 172 ter $\mathrm{CP})^{62}$ esta palabra figure en la propia descripción típica, quizá porque está extendida en el lenguaje común. El legislador podía haber empleado otras expresiones, como hostigar, "molestar a alguien..., insistentemente", o asediar, "presionar insistentemente a alguien". Sin embargo, ha querido exigir expresamente que la conducta se lleve a cabo de forma insistente y reiterada, características que están implícitas en esas voces y que resultarían redundantes. De modo que ha optado por utilizar el verbo acosar, y luego sumar estos adjetivos que denotan la necesidad de permanencia y obstinación en la actuación, de suerte que no bastan actos aislados, y de repetición, que lleva a descartar los comportamientos prolongados cuando no se dan varias veces. En cualquier caso, a diferencia del artículo $182 \mathrm{CP}$-acoso sexual-, en el artículo 172 ter $\mathrm{CP}$ el término acoso no se utiliza para designar el delito, por lo que nada impide que se emplee en la definición típica.

Pero al hablar de acoso en lugar de persecución, como se hace en el $\S 238$ StGB resulta improcedente la cláusula "sin estar legítimamente autorizado", que en Alemania se introdujo para no limitar la libertad de prensa de los periodistas que siguen legítimamente a personas en el ejercicio de su profesión ${ }^{63}$.

61 FISCHER, T.: Strafgesetzbuch und Nebengesetze, 59 Auflage, C. H. Beck, München, 2012, p. 1583; y, KUBICIEL, M./BORUTTA, N.: "Strafgrund...", cit., p. 194.

62 No se utiliza el término acoso en la descripción del artículo 173.1, párrafo 3 CP -acoso inmobiliario-. Sin embargo, en la Exposición de la Ley Orgánica 5/2010, de 22 de junio, por la que se modifica la Ley Orgánica 10/1995, de 23 de noviembre, del Código Penal, se denomina "acoso laboral" y "acoso inmobiliario" a los nuevos delitos introducidos en el artículo 173.1, párrafos 2 y 3 CP. Por otra parte, en el artículo 184.2 CP se habla expresamente de acoso sexual al establecer la pena de la modalidad agravada, pero en el apartado 1, donde se recoge el tipo básico, no se emplea esa expresión, que da nombre al Capítulo III en el que se inscribe.

63 FISCHER, T.: Strafgesetzbuch..., cit., pp. 1581 y 1582. 
En cambio, la actuación de acoso es en todo caso ilícita y no puede ser autorizada ${ }^{64}$, ni legal ni judicialmente ${ }^{65}$. Por eso, tanto el Consejo de Estado, como el Consejo Fiscal, en sus informes al Anteproyecto de reforma del Código penal ${ }^{66}$, proponían dar una nueva redacción a esta disposición, criterio que inexplicablemente no siguió el legislador, seguramente por esa influencia de la normativa alemana.

Por otra parte, el autor ha de llevar a cabo alguna de las conductas descritas "de forma insistente y reiterada". Insistir equivale a persistir o mantenerse firme, o a repetir. Se produce cierta duplicidad en el uso de esos términos típicos. Sin embargo, como he dicho, pienso que de esta forma el legislador deja claro que ha de tratarse de una actuación sistemática, de modo que el sujeto activo tenga la intención de continuar con su actitud de acoso hacia la víctima y, además, que no basta con un solo acto, sino que han de concurrir varios. De manera que, en mi opinión, quien utilice indebidamente datos personales de la víctima una única vez, aunque con ello consiga que numerosas

64 No obstante, en España alude a la actividad de los periodistas, TAPIA BALLESTEROS, P.: El nuevo delito de acoso o stalking, Bosch, Barcelona, 2016, p. 152.

65 ACALE SÁNCHEZ, M.: “Acoso - stalking: art. 173 ter”, en ÁLVAREZ GARCÍA, F.J. (Dir.)/DOPICO GÓMEZ-ALLER, J. (Coord.): Estudio crítico..., cit., p. 566; GALDEANO SANTAMARÍA, A.: “Acoso...”, cit., pp. 570 y ss; MAGRO SERVET, V.: "Reforma...", cit., p. 15; MATALLÍN EVANGELIO, A.: "Delito de acoso...", cit., p. 587; MUÑOZ CONDE, F.: Derecho penal. Parte especial, Tirant lo Blanch, Valencia, 2017, p. 149; PERAMATO MARTÍN, T.: "Los nuevos tipos penales...", cit., p. 7; y, VILLACAMPA ESTIARTE, C.: "El delito de stalking", en QUINTERO OLIVARES, G. (Dir.): Comentario a la reforma de 2015, Aranzadi, Pamplona, 2015, p. 585.

66 Dictamen del Consejo de Estado al Anteproyecto de Ley Orgánica por la que se modifica la Ley Orgánica 10/1995, de 23 de noviembre, del Código Penal, de 27 de junio de 2013. (Disponible en https://www.boe.es/buscar/ doc.php?id=CE-D-2013-358); e, Informe del Consejo Fiscal al Anteproyecto de Ley Orgánica por la que se modifica la Ley Orgánica 10/1995, de 24 de noviembre, del Código Penal, de 20 de diciembre de 2012, p. 144. (Disponible en https://www.uv.es/limprot/boletin10/cf.pdf). 
personas contacten con ella, no realizará el delito ${ }^{67}$. Esta situación puede resultarle sumamente molesta a quien la padece, pero el autor no le genera un clima de hostigamiento personal que coarte su libertad. No lo entiende así el Consejo Fiscal, que en su informe al Anteproyecto de reforma del Código penal ${ }^{68}$ señalaba que "esta insistencia y reiteración no siempre existirá en los supuestos previstos en el artículo 172 ter $1.3^{\circ}$ ya que podrían encuadrarse en este apartado aquellos supuestos en los que se colocan anuncios en un medio de comunicación o en internet que someten a la víctima a continuas llamadas y que sin embargo, el autor del anuncio ha realizado una única conducta que perdura en el tiempo"69.

En cambio, nuestros tribunales han exigido, efectivamente, "que haya un patrón de conducta que se materialice en un plan sistemático de acoso sobre el sujeto pasivo"70, "una estrategia sistemática de persecución, integrada por diferentes acciones dirigidas al logro de una determinada finalidad que las vincule entre ellas" ${ }^{\text {". }}$. Más ampliamente, han argumentado que "el delito de hostigamiento surge de la sistemática reiteración de unas u otras conductas... Se exige implícitamente una cierta prolongación en el tiempo; o, al menos, que quede patente, que sea apreciable, esa voluntad de perseverar en esas acciones intrusivas, que no se perciban como algo puramente episódico o

67 Entiende que esta conducta sí es sancionable, PERAMATO MARTÍN, T.: "Los nuevos tipos penales...", cit., p. 6. Por otra parte, plantea la posibilidad de castigar como autoría mediata, TAPIA BALLESTEROS, P.: El nuevo delito de acoso..., cit., p. 184.

68 Informe del Consejo Fiscal..., cit., pp. 144 y 145. (Disponible en https:// www.uv.es/limprot/boletin10/cf.pdf).

69 De igual opinión, PERAMATO MARTÍN, T.: "Los nuevos tipos penales...", cit., p. 6.

70 SAP de Alicante, 334/2017, de 12 de septiembre (F.J.1). En el mismo sentido, la SJ Instrucción de Tudela de 23 de marzo de 2016 (F.J.1), y la SAP de Teruel 532/2017, de 4 de octubre (F.J.4).

71 SAP de Madrid 491/2017, de 25 de julio (F.J.6). En parecidos términos, la SAP de Madrid 439/2017, de 30 de junio (F.J.5) y la SAP de Madrid 745/2017, de 28 de septiembre (F.J.3). 
coyuntural, pues en ese caso no serían idóneas para alterar las costumbres cotidianas de la víctima"72. También se ha apuntado que "las conductas repetitivas lo han de ser tanto en el número como en el tiempo, pues de otra forma no se entendería la profusión de palabras definidoras de un mismo elemento"73. El Tribunal Supremo, en la sentencia 554/2017, de 12 de julio, afirmó que "de forma insistente y reiterada equivale a decir que se está ante una reiteración de acciones de la misma naturaleza -un continuum-que se repite en el tiempo, en un periodo no concretado en el tipo penal. Ciertamente el tipo penal no concreta el número de actos intrusivos que pueden dar lugar al tipo penal, pero podemos afirmar que este continuum de acciones debe proyectarse en un doble aspecto: a) Repetitivo en el momento en que se inicia. b) Reiterativo en el tiempo, al repetirse en diversas secuencias en tiempos distintos" (F.J.4).

Respecto a los actos entiendo que no puede inferirse del artículo 172 ter $\mathrm{CP}$ la exigencia de un número específico ${ }^{74}$. La actitud del autor tendente a persistir en su actitud de acoso, la afección del bien jurídico protegido y la producción del resultado requerido en el tipo ha de valorarse en cada caso concreto.

Esta postura no es mantenida por algunos autores ${ }^{75}$, que requieren cierta cantidad de acciones, a diferencia de los órganos judiciales que de forma unánime niegan que pueda exigirse de antemano una cifra concreta. De hecho, la STS de la Sala $2^{\mathrm{a}}$ -en Pleno-324/2017, de 8 de mayo, afirmaba que "no es sensato

72 SAP de Pontevedra 576/2017, de 8 de septiembre (F.J.4).

73 SAP de Girona 442/2017, de 21 de julio (F.J.1).

74 Con igual parecer, ALONSO DE ESCAMILLA, A.: "El delito de stalking...”, cit., p. 2; CARPIO BRIZ, D., en CORCOY BIDASOLO, M./MIR PUIG, S. (Dir.): Comentarios ..., cit., p. 625; y, SERRANO GÓMEZ, A., en SERRANO GÓMEZ, A./SERRANO MAÍLLO, A./SERRANO TÁRRAGA, M.D./VÁZQUEZ GONZÁlEZ, C.: Curso de Derecho penal. Parte especial, $4^{\mathrm{a}}$ edición, Dykinson, Madrid, 2017, p. 126.

75 Requiere al menos tres actos de vigilancia o persecución, MATALLÍN EVANGELIO, A.: "Delito de acoso...", cit., p. 583, y más de tres hechos, MUÑOZ CONDE, F.: Derecho penal..., cit., p. 149. 
ni pertinente ni establecer un mínimo número de actos intrusivos como se ensaya en algunas definiciones, ni fijar un mínimo lapso temporal. Pero sí podemos destacar que el dato de una vocación de cierta perdurabilidad es exigencia del delito descrito en el artículo 172 ter CP" "76. También en Alemania, donde el § 238 StGB prevé que la conducta ha de ser persistente, la jurisprudencia ha declarado que no se puede precisar a priori cuántas acciones son necesarias, sino que deben evaluarse en cada supuesto de un modo global. Lo esencial, a juicio del Tribunal Supremo alemán, es que el comportamiento denote una obstinación particular expresada en el delito y una mayor indiferencia del delincuente a la prohibición legal ${ }^{77}$. Igualmente, la doctrina señala que lo fundamental es la permanencia o duración y la perseverancia del autor $^{78}$. En nuestro ordenamiento, en cambio, el artículo 172 ter $\mathrm{CP}$ exige expresamente que haya reiteración, tal vez teniendo en cuenta la experiencia alemana, donde algunos autores han subrayado que según la ley no es necesario este presupuesto ${ }^{79}$, pese a que todos los casos castigados en la jurisprudencia están integrados por varias actuaciones.

Por otra parte, este precepto indica que el autor ha de llevar a cabo el acoso a través de "alguna de las conductas siguientes". Sin embargo, a mi modo de ver esto no implica que

76 En igual dirección, la STS 554/2017, de 12 de julio (F.J.4). También, la SAP de Ceuta 14/2017, de 14 de marzo (F.J.3), y la SAP de Pontevedra 576/2017, de 8 de septiembre (F.J.4).

77 Sentencia del Tribunal Supremo alemán de 19 de noviembre de 2009 (BGH 3 StR 244/09). (Disponible en https://www.hrr-strafrecht.de/hrr/3/09/3-24409.php).

78 EISELE, J., en SCHÖNKE, A./SCHRÖDER, H.: Strafgesetzbuch..., cit., p. 2281; FISCHER, T.: Strafgesetzbuch..., cit., pp. 1583 y ss; KRACK, R./ KISCHE, S.: "Fortgeschrittenenhausarbeit - Strafrecht: Nachstellung mit unverhofften Folgen", en ZJS, 2010, pp. 735 y 736; KÜHL, K.: Strafgesetzbuch: Kommentar, 27 Auflage, C.H.Beck, München, 2011, p. 1092; SCHLUCKEBIER, W., en SATGER, H./SCHMITT, B./WIDMAIER, G.: Strafgesetzbuch Kommentar, 1 Auflage, Carl Heymanns, München, 2009, p. 1431; y, VALERIUS, B.: "Stalking: Der Neue Straftatbestand der Nachstellung in $\S 238$ StGB”, en $J u S, \mathrm{n}^{\circ} 4$, 2007, p. 322.

79 KÜHL, K.: Strafgesetzbuch..., cit., p. 1093. 
no puedan combinarse varias de ellas para realizar el tipo ${ }^{80}$. De lo contrario, bastaría no repetir la misma acción para burlar la condena, incluso aunque los actos de hostigamiento causaran un atentado más grave a la libertad de la víctima, que resultaría impune si no pudiera castigarse a través de otras figuras. Así, por ejemplo, si una persona persigue físicamente a otra, la llama por teléfono, utiliza indebidamente sus datos personales provocando cientos de llamadas, y daña su propiedad, no resultaría penada, por mucho que quien sufre estas intrusiones llevado por el miedo cambie sus condiciones de vida. En cambio, llamadas telefónicas o mensajes reiterados, podrían ser sancionados si la persona acosada se siente afectada en su sentimiento de tranquilidad o seguridad. Por eso, los tribunales con buen criterio vienen apreciando el delito, aunque las conductas de acoso desplegadas no sean las mismas. De hecho, la citada STS de la Sala $2^{a}$-en Pleno-324/2017, de 8 de mayo, señala que "la reiteración de que habla el precepto es compatible con la combinación de distintas formas de acoso. La reiteración puede resultar de sumar acercamientos físicos con tentativas de contacto telefónico, por ejemplo, pero siempre que se trate de las acciones descritas en los cuatro apartados del precepto" ${ }^{81}$. También en la jurisprudencia alemana se sigue este criterio, y el Tribunal Supremo al comentar los elementos esenciales del Nachstellung señala que el delito puede cometerse a través de acciones diferentes ${ }^{82}$.

80 De igual opinión, CARPIO BRIZ, D., en CORCOY BIDASOLO, M./MIR PUIG, S. (Dir.): Comentarios..., cit., p. 627; GALDEANO SANTAMARÍA, A.: "Acoso...", cit., p. 575; PALMA HERRERA en MORILLAS CUEVA, L. (Dir.): Estudios..., cit., p. 406; y, VILLACAMPA ESTIARTE, C.: "Delito de acecho/stalking: art. 172 ter", en ÁLVAREZ GARCÍA, F.J. (Dir.)/DOPICO GÓMEZ-ALLER, J. (Coord.): Estudio crítico..., cit., p. 603. Por el contrario, considera que ha de tratarse de la misma clase de conducta, sin que quepa una combinación de ellas, MATALLÍN EVANGELIO, A.: "Delito de acoso...", cit., p. 582.

81 STS -Sala $2^{\mathrm{a}}$ en Pleno- 324/2017, de 8 de mayo (F.J.4).

82 Sentencia del Tribunal Supremo alemán de 19 de noviembre de 2009 (BGH 3 StR 244/09). (Disponible en https://www.hrr-strafrecht.de/hrr/3/09/3-24409.php). 


\section{Catálogo cerrado de conductas típicas}

$\mathrm{El}$ artículo 172 ter $\mathrm{CP}$ regula en cuatro números las posibles conductas típicas. Se ha eliminado el número 5 previsto en el Anteproyecto de reforma del Código penal, donde se castigaba a quien "realice cualquier otra conducta análoga a las anteriores", reproduciendo la cláusula del número 5 del § 238.1 StGB, que permitía la interpretación analógica en perjuicio del reo.

Pero se acogieron las enmiendas formuladas en el Congreso, precisamente por vulnerar esa analogía in malam partem $^{83}$ y en la versión definitiva de LO 1/2015, de 30 de marzo, no se recoge ese número.

En Alemania, esa disposición se incorporó con el propósito de abarcar las nuevas modalidades comisivas que puedan crearse mediante el desarrollo tecnológico ${ }^{84}$. Pese a ello, ha sido ampliamente criticada tanto por la doctrina como por los tribunales, que han cuestionado incluso su constitucionalidad, por infringir la exigencia de seguridad jurídica derivada del principio de legalidad del $\S 103.2$ de la Ley Fundamental ${ }^{85}$.

Por eso, el Gobierno alemán eliminó esa norma en el Proyecto de reforma ${ }^{86}$ que culminó en la Ley de 1 de marzo de 2017. Sin embargo, algunos expertos pusieron de relieve que su supresión impediría castigar acciones de gravedad semejante a las reguladas: anuncios falsos de muerte o matrimonio, manipulación en redes sociales (por ejemplo, aparecer bajo el nombre de la víctima), dejar ciertos objetos cerca del lugar donde se

83 Enmienda $n^{\circ} 472$ del Grupo Parlamentario Catalán (Convergència i Unió), Enmienda $n^{\circ} 554$ del Grupo Parlamentario Unió, progreso y Democracia, y Enmienda $\mathrm{n}^{\circ} 670$ del Grupo Parlamentario Socialista.

84 FISCHER, T.: Strafgesetzbuch..., cit., p. 1581.

85 KÜHL, K.: Strafgesetzbuch..., cit., p. 1094; y, SCHLUCKEBIER, W., en SATGER, H./SCHMITT, B./WIDMAIER, G.: Strafgesetzbuch..., cit., p. 1430. También la Sentencia del Tribunal Supremo alemán de 19 de noviembre de 2009 (BGH 3 StR 244/09). (Disponible en https://www.hrr-strafrecht.de/hrr/3/09/3-244-09.php).

86 (Disponible en http://dip21.bundestag.de/dip21/btd/18/099/1809946.pdf). 
encuentra (excrementos, cadáveres de animales, etc.), realizar actos de desprecio ante sus superiores, usar programas espía o monitorizar equipos, publicar datos personales en internet, o enviar regalos de manera anónima y continuada ${ }^{87}$. A la vista de estos informes, la Comisión de Asuntos Jurídicos y Protección del Consumidor recomendó conservar dicho precepto ${ }^{88}$ y esta propuesta se trasladó a la versión definitiva de la Ley de 1 de marzo de 2017, que mantuvo el número 5 del $\S 238.1$ StGB.

En este punto el legislador español sí ha corregido la regulación alemana, impidiendo la interpretación analógica perjudicial respecto a un conjunto de conductas que por su amplitud habría dado lugar a una disposición abiertamente contraria a la exigencia de seguridad jurídica derivada del principio de legalidad.

En el número 1 del artículo 172 ter, apartado $1 \mathrm{CP}$, se castiga a quien vigile, persiga, o busque la cercanía física de la persona acosada ${ }^{89}$. Esta norma es mucho más amplia que la equivalente del $\S 238.1 .1 \mathrm{StGB}$, que sólo sanciona la búsqueda de cercanía física. Además, la redacción de este precepto se ha restringido con la reforma de 2017, puesto que antes el tipo hablaba de cercanía espacial, de modo que con el nuevo tenor quedan excluidos los mecanismos que permitan captar a cierta distancia la imagen, y los actos de hostigamiento por medios que no conlleven aproximación personal ${ }^{90}$, como el ejemplo que planteaban algunos autores, donde un hombre usaba repetidamente un globo con mensajes de amor inscritos dirigidos a una

87 Los informes de los expertos acerca del proyecto de reforma pueden consultarse en https://kripoz.de/Kategorie/gesetzentwuerfe/stalking/.

88 Tramitación parlamentaria disponible en http://dipbt.bundestag.de/extrakt/ ba/WP18/762/76261.html.

89 Consideran que la conducta consistente en la búsqueda de cercanía física vulnera el principio de taxatividad, MATALLÍN EVANGELIO, A.: "Delito de acoso...", cit., p. 583; y, MIRÓ LLINARES, F.: "La ciberdelincuencia", en Cuadernos Digitales de Formación, no 46, 2015, p. 5.

90 KÜHL, K.: Strafgesetzbuch..., cit., p. 1093. 
mujer de la que estaba enamorado ${ }^{91}$. No obstante, en Alemania sigue en pie el debate en torno a si es necesario o no el contacto visual entre el acosador y la víctima ${ }^{92}$.

Pues bien, en nuestro ordenamiento algunos tribunales han declarado que esta modalidad típica requiere proximidad física o que la víctima perciba ópticamente al autor ${ }^{93}$. En cambio, otros entienden que también engloba la observación a distancia y a través de dispositivos electrónicos GPS o cámaras de video vigilancia ${ }^{94}$. En la medida en que la búsqueda de cercanía física, la vigilancia y la persecución se prevén de forma separada, creo que no se requiere un acercamiento personal ${ }^{95}$. Ahora bien, para que estos hechos influyan en la persona acosada es necesario que tenga noticia de ellos. De manera que, bien porque ella misma se dé cuenta de que está siendo vigilada o perseguida, o porque se entere por otros medios (porque el acosador le envíe las grabaciones o las cuelgue en internet, se lo comuniquen terceros -vecinos, familiares, compañeros, etc.-...), la vigilancia y la persecución sólo serán delictivas si contribuyen al resultado típico, de modo que los actos de acoso en su conjunto alteran gravemente su vida cotidiana.

En el número 2 se sanciona a quien establece o intenta establecer contacto con la persona acosada a través de cualquier

91 KRACK, R./KISCHE, S.: "Fortgeschrittenenhausarbeit - Strafrecht: Nachstellung mit unverhofften Folgen", en ZJS, 2010, pp 734 y ss. (Disponible en http://www.zjs-online.com/dat/artikel/2010_6_398.pdf).

92 FISCHER, T.: Strafgesetzbuch..., cit., p. 1584; y, KÜHL, K.: Strafgesetzbuch..., cit., p. 1093.

93 SAP de Burgos 170/2017, de 26 de mayo (F.J.2).

94 SJ Instrucción de Tudela de 23 de marzo de 2016 (F.J.1). Mantiene esta opinión, RODRÍGUEZ LAÍN, J.L.: "El nuevo delito de ciberacoso...", cit., p. 29; y, PERAMATO MARTÍN, T.: "Los nuevos tipos penales...", cit., p. 5. Entiende, en cambio, que es necesaria vigilancia física, excluyendo por ejemplo la observancia por Facebook, MAGRO SERVET, V.: "Reforma...", cit., p. 21. Plantea, incluso, el recurso a detectives privados. MUÑOZ CONDE, F.: Derecho penal..., cit., p. 149.

95 Critica la equiparación de estas conductas, TAPIA BALLESTEROS, P.: El nuevo delito de acoso..., cit., p. 160. 
medio de comunicación, o por medio de terceras personas. La redacción es más precisa que la utilizada en el § 238.1.2 StGB, donde se penaliza únicamente a quien intenta contactar con la persona perseguida mediante el uso de medios de telecomunicación u otros medios de comunicación o a través de un tercero, aunque obviamente el contacto efectivo se estima implícito en el tipo. Por otra parte, esta modalidad se interpreta en sentido amplio, abarcando formas de comunicación heterogéneas, tanto verbal como mediante imágenes, símbolos o señales. En la jurisprudencia alemana se han considerado punibles, por ejemplo, el envío de regalos u objetos al domicilio de la víctima, la remisión de cartas a ella o a su empleador ${ }^{96}$, la realización de múltiples llamadas telefónicas no respondidas ${ }^{97}$, además de mensajes de wathsapp, de texto, correo electrónico ${ }^{98}$, etc.

También en España se han castigado por esta vía, las llamadas reiteradas y el envío de $\operatorname{cartas}^{99}$, fotos ${ }^{100}$, regalos, incluso a través de un tercero ${ }^{101}$, las amenazas de suicidio $^{102}$, mensajes en el contestador automático ${ }^{103}$, correos electrónicos ${ }^{104}$, etc., acciones que suelen darse combinadas. Con ello se pone de relieve que la norma analógica no es necesaria para sancionar las for-

96 Sentencia del Tribunal Supremo alemán de 19 de diciembre de 2012 (BGH 4 StR 417/12). (Disponible en https://www.hrr-strafrecht.de/hrr/4/12/4-41712.php?referer=db), y, Sentencia del Tribunal Supremo alemán de 18 de julio de 2013 (BGH 4 StR 168/13). (Disponible en https://www.hrr-strafrecht. de/hrr/4/13/4-168-13.php?referer=db).

97 FISCHER, T.: Strafgesetzbuch..., cit., p. 1585.

98 Sentencia del Tribunal Supremo alemán de 18 de julio de 2013 (BGH 4 StR 168/13). (Disponible en https://www.hrr-strafrecht.de/hrr/4/13/4-168-13. php?referer $=\mathrm{db})$, y, Sentencia del Tribunal Supremo alemán de 15 de febrero de 2017 (BGH 4 StR 375/16). (Disponible en https://www.hrr-strafrecht. de/hrr/4/16/4-375-16.php?referer $=\mathrm{db})$.

99 SAP de León 1101/2017, de 20 de octubre (F.J.1).

100 SJ Instrucción de Tudela de 23 de marzo de 2016 (F.J.1).

101 SAP de Alicante, 334/2017, de 12 de septiembre (F.J.1).

102 SAP de Castellón 261/2017, de 13 de octubre (F.J.1).

103 SAP de Ceuta 14/2017, de 14 de marzo (F.J.3).

104 SAP de A Coruña 416/2017, de 13 de octubre (F.J.1). 
mas comunes de acoso que se dan en la práctica, puesto que las conductas típicas son suficientemente amplias para abarcarlas.

No obstante, en nuestro Derecho se ha censurado la equiparación penológica entre la tentativa y la consumación ${ }^{105}$. Pero no hay que olvidar que el resultado delictivo no lo integra el mero contacto sino la alteración grave de la vida cotidiana, y esta perturbación se puede producir tanto si se consigue efectivamente conectar con la víctima como si se procura reiteradamente y no se logra, siempre que ella conozca estos movimientos del autor. La afectación puede llegar, incluso, a ser más grave si esos intentos son numerosos. Por lo tanto, no me parece que se produzca un quebranto del principio de proporcionalidad ni de las reglas generales de castigo de la tentativa.

En el número 3 se incrimina al que, mediante el uso indebido de datos personales de la víctima, adquiere productos o mercancías, o contrate servicios, o haga que terceras personas se pongan en contacto con ella. Es también una copia del § 238.1.3 StGB. Como antes decía, a mi juicio, la exigencia típica de que el autor lleve a cabo la conducta de forma insistente y reiterada supone bien que repita esta acción, o bien que la realice en conjunción otras, sin que baste la reiteración de actos (contactos) por parte de terceros. Además, con una sola vez faltaría el primer requisito consistente en la insistencia, que se ha interpretado de forma unánime como actuación obstinada, tenaz, sistemática que revele la intención del autor de desarrollar un comportamiento persistente y duradero.

En la práctica judicial hay alguna sentencia donde se enjuicia el uso indebido de datos como modalidad de acoso, pero

105 ALONSO DE ESCAMILLA, A.: "El delito de stalking...”, cit., p. 6.; GOIKOLEA MARTÍN, L.A.: "Derecho de familia y Derecho penal. Novedades del Código penal en virtud de la Ley Orgánica 1/2015 y jurisprudencia penal", en Cuadernos Digitales de Formación, no 39, 2016, p. 4; MARTÍNEZ MUÑOZ, C.J.: "El «nuevo» delito de acoso...”, cit., p. 7; MATALLÍN EVANGELIO, A.: "Delito de acoso...", cit., p. 583; y, MIRÓ LLINARES, F.: "La ciberdelincuencia", cit., p. 6. 
se trata de un empleo reiterado, puesto que el autor introduce el correo electrónico de la afectada en varias páginas de contactos, recibiendo infinidad de mensajes y, además, se recogen otros hechos (el autor ató un perro a la puerta de su ex mujer, etc.). Sin embargo, los actos descritos se estimaron insuficientes para aplicar el artículo 172 ter CP. Dice el tribunal que "se exige implícitamente una cierta prolongación en el tiempo; o, al menos, que quede patente, que sea apreciable esa voluntad de perseverar en esas acciones intrusivas, que no se perciban como algo puramente anecdótico o coyuntural, pues en este caso no serían idóneas para alterar las costumbres cotidianas de la víctima... No hay datos en el supuesto..., para entender presente la voluntad de imponer un patrón de conducta sistemático de acoso con vocación de cierta perdurabilidad temporal"106. Si la utilización repetida de datos personales, provocando numerosos contactos indeseados no se estima suficiente para completar el tipo, uno sólo quedará claramente excluido, salvo que vaya acompañado de otras conductas de acoso.

En el número 4 se pena a quien atente contra la libertad o contra el patrimonio de la persona acosada o de otra persona próxima a ella. Esta disposición sí dista sustancialmente de la prevista en el $\S 238.1 .4 \mathrm{StGB}$, que prevé la conducta de amenazar a la víctima con lesionar la vida, integridad física, salud o libertad propia o de uno de sus parientes o cualquier otra persona cercana a ellos. En este sistema las amenazas a estos bienes se entienden comprendidas en el Nachstellung, aunque la jurisprudencia admite la aplicación de las reglas del concurso de leyes ${ }^{107}$. De forma que si revisten cierta gravedad son sancionadas por el delito de amenazas ( $\$ 241 \mathrm{StGB})$, que puede concurrir en concurso ideal con el $\S 238$ StGB si se dan otros actos de hostigamiento suficientes para realizarlo. Las amenazas contra otros bienes jurídicos son punibles conforme a las normas de esta figura, que al igual que los demás delitos cometidos durante el

106 SAP de Lugo 122/2017, de 28 de junio (F.J.2).

107 KÜHL, K.: Strafgesetzbuch..., cit., p. 1093. 
Nachstellung (injurias, daños, etc.) se castigan en concurso ideal con el $\S 238 \mathrm{StGB}^{108}$. No obstante, la puesta en peligro de la vida y la salud, o la producción de la muerte de la víctima o de personas cercanas, se regulan en tipos cualificados en esta norma.

Por el contrario, el artículo 172 ter CP no contempla las amenazas entre las conductas típicas. Llama la atención que el legislador haya omitido esta modalidad delictiva teniendo en cuenta que el Convenio de Estambul determina la obligación de tipificar los comportamientos amenazantes realizados de modo repetido que lleven a la persona afectada a temer por su seguridad. Esto supone que las amenazas no quedan consumidas en el acoso, sino que según el apartado 3 se castigan en concurso real. Sin embargo, a mi modo de ver la solución correcta es la adoptada en Alemania, puesto que ambos delitos protegen la libertad de decisión de la víctima. De manera que, si es amenazada durante el acoso, se debería aplicar un concurso de normas, sin perjuicio de apreciar un concurso de delitos si hay otros actos de acoso graves además de las amenazas.

En realidad, nuestros tribunales aplican esta solución, de modo que las amenazas menores se incluyen en el acoso (por ejemplo, reclamar un pago no debido y amenazar con denunciar si no se cumple $)^{109}$, y las más graves se castigan en concurso real ${ }^{110}$. Sin embargo, respecto a las coacciones, aunque se reconoce también que el bien jurídico reside como en el acoso en la libertad de obrar ${ }^{111}$, alguna resolución ha castigado actos coactivos leves separadamente (en concreto, dejar un cartel pidiendo la devolución de ciertos objetos, junto con una bolsa de basura con un tarro, un jarrón y un reloj lleno de excrementos, lo que el

108 EISELE, J., en SCHÖNKE, A./SCHRÖDER, H.: Strafgesetzbuch..., cit., pp. 2288 y 2289 ; FISCHER, T.: Strafgesetzbuch..., cit., p. 1593; y, KINDHÄUSER, U.: Strafgesetzbuch. Lehr- und Praxiskommentar, 5 Auflage, Nomos, Bade-Baden, 2013, p. 847.

109 SAP de León 1101/2017, de 20 de octubre (F.J.1).

110 SAP de Pontevedra 66/2017, de 31 de marzo (F.J.1).

111 AAP de Murcia 774/2017, de 21 de septiembre (F.J.3). 
tribunal interpretó como violencia psíquica $)^{112}$. En mi opinión, estas acciones, que se califican impropiamente como coacciones realizando una interpretación extensiva de la violencia, deben integrarse en el acoso y sólo castigarse en concurso real las coacciones que revisten cierta gravedad, sin valorarlas entonces en el artículo 172 ter $\mathrm{CP}^{113}$.

En cambio, se tipifican los atentados contra la libertad y contra el patrimonio. La libertad se ha de referir a la de movimiento, al igual que se interpreta en Alemania ${ }^{114}$, puesto que la de decidir y de obrar son el objeto de tutela del artículo 172 ter CP. Por otra parte, el propio legislador en la Exposición de Motivos de la LO 1/2015, de 30 de marzo, señala que el nuevo tipo de acoso trata de dar respuesta a "todos aquellos supuestos en los que, sin llegar a producirse necesariamente el anuncio explícito o no de la intención de causar algún mal (amenazas) o el empleo directo de violencia para coartar la libertad de la víctima (coacciones), se producen conductas reiteradas por medio de las cuales se menoscaba gravemente la libertad y sentimiento de seguridad de la víctima..." $" 115$. En consecuencia, las ofensas a la libertad comprendidas en el acoso, en principio, no son las constitutivas de estos delitos. El problema a la hora de interpretar el número 4 del apartado 1 es su conciliación con el apartado 3, en el que se dispone la punición separada de los delitos en que se hubieran concretado los actos de acoso. Los ataques a la libertad y al patrimonio comprendidos en el artículo 172 ter CP deberían ser hechos menores no constitutivos de delito, como una breve

112 SAP de Pontevedra 66/2017, de 31 de marzo (F.J.1).

113 Considera que se vulnera el "non bis in ídem" si se condena, además, por amenazas o coacciones, CARPIO BRIZ, D., en CORCOY BIDASOLO, M./ MIR PUIG, S. (Dir.): Comentarios..., cit., p. 627 y 628.

114 KÜHL, K.: Strafgesetzbuch..., cit., p. 1093.

$115 \mathrm{Se}$ muestra partidario de mantener la criminalización del hostigamiento en los delitos de amenazas y coacciones, de modo que sólo sean típicas las objetivamente adecuadas para alterar la libertad de decidir o la libertad de obrar, BAUCELLS LLADÓS, J.: "La irreflexiva criminalización...", cit., p. 12 . 
retención o unos daños insignificantes. Si se trata de hechos delictivos, y se aprecian para integrar el acoso y, además, se penan conforme a la correspondiente figura, se vulnera el principio ne bis in idem.

Efectivamente, nuestros órganos judiciales han mantenido una interpretación restrictiva entendiendo consumidos los daños menores en el delito de acoso. Así, hechos como romper el retrovisor de un vehículo, o pincharle una rueda, se han descrito como actos de hostigamiento pero no han dado lugar a una penalidad separada ${ }^{116}$.

En Alemania, además de la cláusula analógica del número 5 del apartado 1, en el $\S 238$ StGB se prevén dos tipos agravados. En el apartado 2 se incrementa la pena si el autor pone a la víctima, un pariente $\mathrm{u}$ otra persona cercana a ella en peligro de muerte o grave daño a la salud. En el apartado 3 cuando el delincuente causa la muerte de la víctima, o de otra persona cercana a ella. Estas normas han tenido aplicación especialmente en supuestos en los que debido a los actos de acoso la víctima se suicida ${ }^{117}$. Para condenar por el resultado cualificado la jurisprudencia ha exigido que exista una relación directa entre la conducta delictiva básica y la creación del peligro para el bien jurídico finalmente lesionado, de modo que este resultado fuera previsible para el autor concreto ${ }^{118}$.

El artículo 172 ter CP no recoge estas ofensas a tales bienes jurídicos, omisión que tachó de injustificada el Consejo

116 SAP de Burgos 170/2017, de 26 de mayo. No obstante, en este caso se incluyen esos daños en la narración de hechos probados relativos al comportamiento de acoso, indicando que se sospechaba que los había causado el denunciante. Sin embargo, la Audiencia Provincial estima el recurso y absuelve al acusado del delito de acoso por no haber quedado suficientemente acreditados los hechos imputados.

117 EISELE, J., en SCHÖNKE, A./SCHRÖDER, H.: Strafgesetzbuch..., cit., pp. 2287 y 2288; y, KINDHÄUSER, U.: Strafgesetzbuch ..., cit., p. 846.

118 Sentencia del Tribunal Supremo alemán de 15 de febrero de 2017 (BGH 4 StR 375/16). (Disponible en https://www.hrr-strafrecht.de/hrr/4/16/4-37516.php?referer $=\mathrm{db})$. 
de Estado en su Informe al Anteproyecto ${ }^{119}$. Por lo tanto, regirá la regla concursal del apartado 3. Si durante el acoso o como consecuencia del mismo se producen lesiones a la víctima o se le causa la muerte, o si se pone en peligro su vida o integridad física, estos hechos se castigarán en concurso real con el acoso, siempre que el resto de conductas revistan la gravedad necesaria para integrar este delito, pues el principio non bis in idem impide sancionarlos dos veces.

\section{Penalidad y persecución}

La penalidad prevista para el tipo básico del artículo 172 ter $\mathrm{CP}$ es prisión de tres meses a dos años o multa de seis a veinticuatro meses. El $\S 238.1$ StGB establece una pena de prisión de hasta tres años o multa. Esta sanción mayor se corresponde con la interpretación rigurosa que vienen haciendo los tribunales, apreciando el delito sólo cuando se acreditan actos graves de hostigamiento y repercusiones importantes en las circunstancias de la vida externa. De hecho, hay un artículo ("Stalking in allen Instanzen - Kritische Bestandsaufnahme erster Entscheidungen $z u \S 238$ StGB") donde se censura la inaplicación del Nachstellung a hechos que presentan cierta similitud con algunos que en nuestro país sí han dado lugar al delito de acoso. En un caso, el autor realizó multitud de mensajes y llamadas, al domicilio y al lugar de trabajo, que determinaron a la víctima a cambiar temporalmente de residencia ${ }^{120}$. En otro, la acusada envió numerosos mensajes con contenido sexual y visitó en reiteradas ocasiones el puesto laboral y la vivienda de la persona perseguida, dejándole incluso prendas en su interior, lo que llevó al afectado a adoptar medidas para evitarlo, viviendo en un clima de amenaza constante que tuvo repercusiones en su salud ${ }^{121}$. Por otra parte, en la jurisprudencia posterior se ha mantenido esta línea restric-

119 Dictamen del Consejo de Estado..., cit. (Disponible en https://www.boe.es/ buscar/doc.php?id=CE-D-2013-358).

120 KRÜGER, M.: “Stalking... ", cit., p. 546.

121 KRÜGER, M.: "Stalking...”, cit., pp. 546 y 547. 
tiva y sólo se castigan comportamientos verdaderamente serios que motiven alteraciones trascendentes en el estilo de vida, resultando irrelevantes las repercusiones psíquicas o incluso las lesiones psicológicas ${ }^{122}$.

En nuestra práctica judicial se sancionan hechos menores, debido a que se hace una lectura excesivamente flexible del resultado típico. Pese a que el tenor del artículo 172 ter $\mathrm{CP}$ requiere que el sujeto activo "altere gravemente el desarrollo de la vida cotidiana", con tenor semejante al previsto en el $\S 238$ StGB antes de la reforma de 2017, se estima suficiente que la víctima se haya visto afectada psíquicamente, o incluso que la acción se estime adecuada para ello. Por eso, la menor sanción resulta proporcionada, teniendo en cuenta que la disposición del apartado 3 obliga a castigar las acciones delictivas aparte.

Si se trata de una persona especialmente vulnerable por razón de su edad, enfermedad o situación, se impondrá la pena de prisión de seis meses a dos años. Esta disposición no figuraba en el Anteproyecto, pero se añadió por recomendación del Consejo General del Poder Judicial, que consideraba conveniente extender el tipo agravado previsto para el ámbito familiar a otros supuestos en que el ofendido fuera especialmente vulnerable por los motivos apuntados ${ }^{123}$. Lo llamativo es la diferencia que se

122 Sentencia del Tribunal Supremo alemán de 19 de diciembre de 2012 (BGH 4 StR 417/12). (Disponible en https://www.hrr-strafrecht.de/hrr/4/12/4-41712.php?referer=db), Sentencia del Tribunal Supremo alemán de 18 de julio de 2013 (BGH 4 StR 168/13). (Disponible en https://www.hrr-strafrecht.de/ hrr/4/13/4-168-13.php?referer=db), Sentencia del Tribunal Supremo alemán de 16 de junio de 2014 (BGH 4 StR 111/14). (Disponible en https://www. hrr-strafrecht.de/hrr/4/14/4-111-14.php?referer=db), y, Sentencia del Tribunal Supremo alemán de 15 de febrero de 2017 (BGH 4 StR 375/16). (Disponible en https:/www.hrr-strafrecht.de/hrr/4/16/4-375-16.php?referer=db).

123 Informe del Consejo General del Poder Judicial al Anteproyecto de Ley Orgánica por la que se modifica la Ley Orgánica 10/1995, de 23 de noviembre, del Código Penal, de 16 de enero de 2013, p. 145. (Disponible en http:// www.poderjudicial.es/cgpj/es/Poder_Judicial/Consejo_General_del_Poder_Judicial/Actividad_del_CGPJ/Informes/Informe_al_Anteproyecto_ de_Ley_Organica_por_la_que_se_modifica_la_Ley_Organica_10_1995 de_23_de_noviembre_del_Codigo_Penal). 
establece con la cualificación aplicada a las personas del artículo 173.2 CP, donde se incrementa la pena de prisión, que pasa a ser de uno a dos años, elevando el mínimo, pero curiosamente se añade la de trabajos en beneficio de la comunidad de sesenta a ciento veinte días.

Sin embargo, la defectuosa técnica legislativa de estas normas se pone de manifiesto cuando concurren las dos causas de agravación, porque la víctima vulnerable es alguna de las enumeradas en el artículo 173.2 CP. En estos casos parece que debe primar la cualificación prevista para las personas recogidas en esta norma, puesto que la pena de prisión es mayor. Pero como contrapunto se prevé la posibilidad de aplicar alternativamente una pena de trabajos en beneficio de la comunidad, que el legislador no quiso contemplar para las personas vulnerables. Es fácil ver que la solución más racional es aplicar la pena de prisión señalada en ese precepto para las personas pertenecientes al ámbito doméstico. Pero en realidad se deja en manos del juez una sanción que debería precisar la ley, porque ni siquiera las reglas de concurso de leyes aportan una solución. De acuerdo con el principio de alternatividad del artículo $8.4 \mathrm{CP}$, el juzgador puede decantarse por el artículo $173.2 \mathrm{CP}$, que recoge la pena de prisión superior, o por el tipo previsto para los inimputables, que no contempla la posibilidad de trabajos.

Por otra parte, aunque el supuesto más frecuente de acoso es el que realiza el hombre respecto a la mujer que ha sido su esposa o su pareja sentimental, la agravación se aplica a todas las personas pertenecientes al ámbito doméstico, siguiendo las directrices del Convenio de Estambul de 2011.

En estas disposiciones el artículo 172 ter $\mathrm{CP}$ se aparta del $\S 238$ StGB creado en 2007, que no contempló estas cualificaciones relativas a las personas vulnerables o pertenecientes al núcleo familiar, ni las ha incorporado tampoco con la reforma de 2017, seguramente porque en la práctica judicial no se plantean supuestos que afecten a esas personas, salvo los casos comunes de ex parejas. En realidad, el Convenio de Estambul sólo obliga a tipificar determinadas conductas que recaen en la mujer o en los 
parientes, entre ellas el acoso. Pero una vez reguladas no dispone que, además, se agrave la pena cuando el comportamiento se dirija frente a ellos. En cambio, en el acoso, que puede constituir violencia de género si lo comete el hombre sobre su ex pareja, se incrementa la penalidad, a diferencia del delito de malos tratos habituales del artículo $173.2 \mathrm{CP}$, que no establece una sanción mayor en tal caso.

Cuando las acciones de acoso cumplan las exigencias del artículo $173.2 \mathrm{CP}$, en principio, prevalece sobre el artículo 172 ter, apartado $2 \mathrm{CP}$, en aplicación de las reglas del concurso de leyes ${ }^{124}$, consumiendo los atentados más graves a la dignidad los actos menores contra la libertad que culminan en un clima de dominación que afecta a aquel bien jurídico. Ahora bien, se advierte de nuevo una descompensación penológica, puesto que en el primer precepto la prisión es de seis meses a tres años, frente a la de uno a dos años del segundo, de manera que el mínimo es superior en esta norma, aunque se prevén alternativamente trabajos en beneficio de la comunidad.

En el apartado 3 del artículo 172 ter CP se dispone que las penas previstas en este artículo se impondrán sin perjuicio de las que pudieran corresponder a los delitos en que se hubieran concretado los actos de acoso. Esta norma determina la aplicación de las reglas del concurso real ${ }^{125}$, puesto que de no existir esta previsión expresa regirían normalmente las disposiciones del concurso ideal. Como señala la Fiscalía General del Estado ${ }^{126}$,

124 Aplica los principios de especialidad o alternatividad, GOIKOLEA MARTÍN, L.A.: "Derecho de familia y Derecho penal...", cit., pp. 5 y 6.

125 CUERDA ARNAU, M.L., en GONZÁLEZ CUSSAC, J.L. (Coord.): Derecho penal..., cit., p. 176; y, PERAMATO MARTÍN, T.: "Los nuevos tipos penales...", cit., pp. 8 y 9. Entiende, en cambio, que rigen las reglas del concurso medial, en virtud del artículo 172 ter, apartado $3 \mathrm{CP}$, cuando los medios empleados para el acoso son delictivos, QUERALT JIMÉNEZ, J.J.: Derecho penal español, cit., p. 178.

126 Conclusiones del XII Seminario de Fiscales Delegados en Violencia sobre la Mujer - Año 2016. Documento de la Fiscalía General del Estado de 24 de marzo de 2017, pp. 25 y 26. (Disponible en https://www.fiscal.es/fiscal/ 
se ha seguido el mismo criterio que en el artículo 173.2 CP y, en general, en los delitos contra la integridad moral por mandato del artículo $177 \mathrm{CP}$.

La solución adoptada es distinta a la aplicada en Alemania, donde el $\S 238$ StGB no contiene ninguna regla concursal específica. No obstante, incluye las amenazas a algunos bienes entre las formas de conducta, lo que hace que queden comprendidas en el Nachstellung, salvo que por su gravedad prevalezca el $\S 241$ StGB en virtud de las disposiciones del concurso de leyes. Pero incluso en este supuesto ambas infracciones se aprecian en concurso ideal, cuando los demás actos de hostigamiento presentan bastante entidad para colmar el tipo. Esta misma modalidad concursal rige, también, cuando durante el acecho se atenta contra otros bienes jurídicos.

Pues bien, como antes decía, creo que la respuesta en el caso de las amenazas debe ser similar en nuestro sistema, dando entrada a las normas del concurso de leyes, si no se quiere incurrir en una infracción del principio ne bis in idem, sancionando doblemente la ofensa a la libertad de decisión. En cambio, cuando los actos afecten a otros bienes jurídicos, a tenor del citado apartado 3 procederá aplicar las reglas del concurso real. Esta solución sería apropiada cuando esos otros ilícitos conllevan un resultado material (daños, lesiones, muerte, etc.), en la media en que la unidad de hecho del artículo $77 \mathrm{CP}$ equivale a unidad del objeto de valoración, incluyendo el resultado material. Desde esta perspectiva, cuando hay varios resultados materiales no hay unidad de hecho y, por tanto, procede apreciar un concurso real ${ }^{127}$. En cambio, si las distintas ofensas producidas durante el acoso

publico/ciudadano/fiscal_especialista/violencia_sobre_mujer/documentos_normativa/!ut/p/a0/04_Sj9CPykssy0xPLMnMz0vMAfGjzOI9HT0cDT2DDbzcfSzcDBzdPYOdTD08jE0MDfULsh0VAb30hIA!/?numElemento sPorPagina $=10 \&$ paginaDestino $=1$ ).

127 COBO DEL ROSAL, M./VIVES ANTÓN, T.S.: Derecho penal. Parte general, $5^{\text {a }}$ edición, Tirant lo Blanch, Valencia, 1999, pp. 771 y ss; y, ORTS BERENGUER, E./GONZÁleZ CUSSAC, J.L.: Compendio de Derecho penal. Parte general, $7^{\mathrm{a}}$ edición, Tirant lo Blanch, Valencia, 2017, p. 48. 
afectan a bienes inmateriales, como el honor, en sentido técnico la modalidad pertinente sería el concurso ideal. Sin embargo, en ambos casos el artículo 172 ter, apartado $3 \mathrm{CP}$, establece la condena del acoso y de los demás delitos por separado. Pese a ello, la valoración de una misma conducta como elemento del tipo de acoso y a su vez como hecho constitutivo de otro delito implicaría una violación del principio ne bis in ídem, por lo que sólo podrán castigarse como ilícitos separados si los restantes actos de hostigamiento cubren las exigencias del artículo 172 ter CP.

Un supuesto particular se plantea cuando el sujeto activo quebranta la orden de alejamiento y acosa a la persona protegida. En esta situación debería apreciarse un concurso ideal, porque sancionar esa aproximación como acercamiento físico constitutivo de acoso y como quebrantamiento de condena o medida cautelar conllevaría una quiebra del non bis in ídem ${ }^{128}$. Pero en virtud del apartado 3 se castigarán por separado sin tomar en consideración el quebrantamiento como acto de acoso.

Finalmente, el apartado 4 dispone que los hechos descritos en este artículo sólo serán perseguibles mediante denuncia de la persona agraviada o de su representante legal. En este punto, nuestra legislación aventaja a la alemana, puesto que hasta la reforma de 2017 el Nachstellung era un delito privado que sólo se perseguía a instancias del agraviado y no del Fiscal, salvo que hubiera un interés público extraordinario ${ }^{129}$. Esto se entendió como un abandono a estas víctimas por parte del estado, precisamente en unos hechos que cada vez producen una mayor indignación social ${ }^{130}$. No obstante, la ley de reforma de 2017 ha

128 De esta opinión, PERAMATO MARTÍN, T.: "Los nuevos tipos penales...", cit., pp. 78 y 79; y, Conclusiones del XII Seminario de Fiscales Delegados en Violencia sobre la Mujer..., cit., p. 27.

$129 \mathrm{Al}$ respecto, EISELE, J., en SCHÖNKE, A./SCHRÖDER, H.: Strafgesetzbuch..., cit., p. 2289.

130 CONZELMANN, Y.: "Stalking ist keine Privatsache", Legal Tribune on Line, de 20 de febrero de 2017. (Disponible en https://www.lto.de/recht/ hintergruende/h/238-stgb-neufassung-stalking-gefaehrdungsdelikt-privatsache-schwachstellen/). 
suprimido este ilícito del catálogo de delitos privados previstos en la ley procesal ( $\$ 374 \mathrm{StPO})$, manteniendo únicamente la necesidad de denuncia en el apartado 4 del $\S 238$ StGB.

Por otra parte, el artículo 172 ter, apartado 2 CP, excluye la exigencia de denuncia cuando la persona ofendida sea alguna de las protegidas en el artículo 173.2 CP, excepción que resulta lógica teniendo en cuenta que el especial vínculo que existe entre las partes y la presión psicológica que padece la víctima pueden llevarla a no denunciar, bien por temor, o por pensar que los actos de hostigamiento forman parte de su esfera privada. Esta disposición se introdujo a propuesta de varias enmiendas presentadas en el Congreso, en las que se argumentaba que el espíritu de la LO 1/2004 de Medidas de Protección Integral de Violencia de Género, así como toda la legislación introducida por las diversas reformas en materia de violencia de género y/o doméstica, no eran coherentes con el requisito de denuncia previa para poder investigar, instruir y enjuiciar cualquier delito de dicho ámbito ${ }^{131}$.

\section{Conclusiones}

El artículo 172 ter CP ha seguido el modelo del $\S 238$ $\mathrm{StGB}$, con algunas mejoras que tratan de solventar deficiencias advertidas en ese país, pero también con algunas incoherencias, motivadas por una inadecuada traslación del precepto alemán, además de conservar la exigencia relativa al resultado, censurada de manera unánime y que recientemente ha sido suprimida en Alemania.

En el artículo 172 ter CP se utiliza el verbo acosar, precisando que ha de hacerse de forma insistente y reiterada, mientras en el $\S 238$ StGB se habla de perseguir de modo persistente. Es cierto que el término acosar tal vez no es el más idóneo para

131 Enmienda $n^{\circ} 554$ del Grupo Parlamentario de Unión Progreso y Democracia, y Enmienda $n^{\circ} 670$ del Grupo Parlamentario Socialista. 
definir la conducta, pero su significado, perseguir sin dar tregua o apremiar de forma insistente con molestias o requerimientos, unido a las acciones típicas expresa la idea de hostigamiento que se quiere tipificar. A continuación, la doble exigencia recogida por el legislador implica tanto la persistencia como la repetición. Por otra parte, a diferencia del artículo 182 CP -acoso sexual-, el artículo 172 ter CP no va encabezado por la denominación acoso, lo que haría improcedente utilizar esta expresión en la definición del delito. De esta forma se salvan las objeciones formuladas en Alemania al término persecución (Nachtellung), dado que puede ser un comportamiento plenamente legítimo. Además, en la medida en que cabe una persecución lícita, se incorporó la cláusula "de manera no autorizada", con el fin de no coartar la libertad de prensa de los periodistas. En cambio, el uso de esta causa de atipicidad en el acoso ha motivado fundadas críticas en nuestro Derecho, porque una actuación abusiva en sí no puede nunca autorizarse.

A continuación, se tipifican varias conductas en un listado cerrado que no permite castigar otras distintas al haberse suprimido el apartado 5 del artículo 172 ter CP que figuraba en el Anteproyecto de reforma. Por el contrario, esta disposición se mantiene en el $\S 238.1$ StGB tras la ley de 2017, pese a las amplias objeciones recibidas por conculcar el principio de certeza, al considerarse necesaria para sancionar comportamientos de gravedad equivalente a los previstos. Sin embargo, en nuestro ordenamiento se rechazó ese apartado por estimarlo contrario a la prohibición de analogía in malam partem. A mi juicio, aunque se trataba en realidad de un supuesto de interpretación analógica, la amplitud de las acciones típicas y la falta de precisión de algunas de ellas hacían que esa cláusula resultara abiertamente contraria a la seguridad jurídica y al principio de legalidad. De hecho, la práctica forense demuestra que los actos más comunes de acoso tienen perfecta cabida en las conductas previstas.

Esas acciones sólo dan lugar al delito si se realizan de manera repetida, incluso en el caso del uso abusivo de datos personales de la víctima que desencadena multitud de contactos por 
parte de terceros. En contra de la interpretación mantenida por el Consejo Fiscal, entiendo que no puede prescindirse del requisito de la reiteración, por el sujeto activo y que este presupuesto no se cumple si no realiza varias veces esa $u$ otras acciones, por mucho que sí se dé una pluralidad de actos por parte de otras personas hacia la acosada. Asimismo, en caso de utilizar el autor esa información una sola vez, su conducta carecería del carácter sistemático que requiere el tipo, de modo que revele un patrón de conducta y una actitud persistente de hostigamiento hacia la parte afectada. Tampoco este segundo elemento puede colmarse con las actuaciones de quienes entablan o intentan establecer conexión con la víctima. Así lo ha interpretado alguna sentencia, que ha absuelto incluso habiendo insertado el acusado los datos personales en varias páginas web, provocando numerosos mensajes hacia la demandante.

Del mismo modo, pienso que no se puede fijar a priori un número de actos necesarios para completar el delito, puesto que en cada caso se deberá comprobar la tendencia del autor a persistir en su actitud y la efectiva alteración grave de la vida cotidiana. También en este punto hay coincidencia en la práctica forense, al igual que en la jurisprudencia alemana.

Por otra parte, creo que el delito puede realizarse tanto mediante la repetición de la misma acción, como combinando varias distintas. De hecho, entre los supuestos enjuiciados en nuestros tribunales no se encuentran apenas casos en los que el acoso se cometa con una misma modalidad de conducta. Sería absurdo exigir esa homogeneidad porque se estaría brindando a quien realiza el hostigamiento la posibilidad de eludir la condena, simplemente variando su forma de acosar. Tanto nuestros órganos judiciales como los alemanes son unánimes en este sentido.

Las conductas típicas coinciden parcialmente con las recogidas en el 238.1 StGB y reflejan en general las que se dan en la realidad en los sucesos de acecho. En esta norma se prevé como primera conducta la búsqueda de cercanía física, a la que el artículo 172 ter, apartado $1 \mathrm{CP}$, añade la persecución y 
la vigilancia. La tipificación de esta última modalidad creo que supone la admisión de formas indirectas de acercamiento, mediante artilugios tecnológicos, cuyo uso ha llevado en Alemania a plantear su posible castigo como forma de acercamiento físico. Su previsión expresa posiblemente ha querido cubrir esta laguna que se advierte en el sistema germánico. En nuestro país un sector doctrinal ha criticado la imprecisión de este número 1 . Sin embargo, la necesidad de que se altere gravemente la vida cotidiana de la persona acosada resta relevancia a que el acosador se halle más o menos cerca de ella, porque sólo si conoce esas intrusiones y si le influyen psicológicamente pueden tenerse en cuenta para la realización del tipo. En este sentido, entiendo que es bueno que el legislador haya resuelto una cuestión controvertida en el Derecho alemán, contemplando actuaciones que pueden producir el mismo resultado que el acercamiento físico, como grabar y enviar videos a la víctima o colgarlos en internet.

La tipificación del contacto e intento de contacto a mi juicio no suponen una quiebra del principio de proporcionalidad ni de las reglas de la tentativa. En este delito se penalizan acciones que en sí son atípicas, de suerte que no constituyen tentativa en sentido penal. Lo relevante es que esos actos considerados globalmente produzcan una alteración grave en el desarrollo de la vida, y a estos efectos pueden ejercer la misma influencia los intentos reiterados de conectar con la víctima que el contacto efectivo, sobre todo si en el primer caso el número de intentos es mayor. Sí entiendo que se ha mejorado la regulación alemana al contemplar el contacto efectivo, que en ese país se omite.

Respecto a los atentados a la libertad o el patrimonio, considero que deben entenderse referidos a las limitaciones leves de la libertad de movimiento y a los pequeños daños al patrimonio, englobándolos en el delito de acoso. Si los hechos contra esos bienes revisten una trascendencia mayor, entrará en juego el apartado 3 del artículo 172 ter CP y en mi opinión, deberán sancionarse por separado conforme al tipo correspondiente, pero sin valorarlos además para completar el acoso porque entonces se infringiría el principio non bis in ídem. Esta misma solución 
se debe aplicar a las amenazas, pese a no encontrarse entre las conductas típicas, en la medida en que afectan a la libertad de decisión, por lo que o bien se entienden consumidas en el acoso, o si son graves se penarán por separado y no formarán parte de ese ilícito.

Como resultado de estas conductas, realizadas de forma insistente y reiterada se ha de producir una alteración grave del desarrollo de la vida cotidiana. En este punto la interpretación de los tribunales españoles y de los alemanes dista sustancialmente. En Alemania se ha exigido que la persona perseguida haya adoptado cambios sustanciales en sus hábitos de vida externa, los daños psicológicos incluso graves son irrelevantes para el nacimiento del delito, salvo que tengan repercusiones de esa índole, por ejemplo, por ocasionar una baja laboral. La reforma de 2017 ha eliminado esta exigencia, y basta la adecuación objetiva de la conducta para provocar ese resultado. Se ha acabado así con la aleatoriedad que suponía supeditar el delito a la reacción de la persona perseguida, y este criterio se ha sustituido por la idoneidad objetiva de la acción para provocar esos cambios, y en definitiva por la gravedad de la conducta. Como explicaba el Ministro de justicia al comentar la reforma, el stalking será punible incluso cuando la víctima no ceda a la presión y no modifique su forma de vida, bastará que la conducta sea objetivamente capaz de provocar ese efecto ${ }^{132}$.

Nuestros tribunales han adoptado de facto una interpretación semejante y han considerado realizado el resultado típico cuando la persona acosada sufre una presión psíquica que le ocasiona inseguridad o intranquilidad. Incluso les basta que esos efectos psicológicos se vean como una consecuencia normal del comportamiento del autor, con independencia de la repercusión concreta que haya tenido.

Pero debido a esa lectura laxa se han dictado sentencias condenatorias por actuaciones de mucha menor gravedad a las

132 (http://www.bmjv.de/SharedDocs/Pressemitteilungen/DE/2016/07132016_ Kabinett_Schutz_Stalking.html). 
que se sancionan en la práctica judicial alemana en aplicación de disposiciones en algunos casos idénticas. Por eso decía que el hecho de que este delito lo sufran en mayor medida las mujeres, principalmente por parte de sus ex parejas, no puede llevar a suavizar las exigencias del principio de intervención mínima. Y en este caso entiendo que este principio impide castigar acciones que causen simplemente intranquilidad o inquietud, o que afectan negativamente al ánimo de la víctima, como se lee en algunas resoluciones que aportan estos efectos como fundamento de la pena.

En consecuencia, creo que debe suprimirse el resultado típico, como se ha hecho en Alemania, para no subordinar la realización del delito a la respuesta de la víctima, lo que puede conducir a consecuencias desproporcionadas sancionando acciones de inferior entidad a otras que resultan impunes por no ceder la persona acosada a la presión de quien realiza el hostigamiento.

Ahora bien, la eliminación de ese elemento debe ir acompañada de un mayor rigor en la valoración de la adecuación de la conducta para alterar gravemente el desarrollo de la vida de la víctima. En definitiva, los órganos judiciales han de exigir que el comportamiento revista suficiente trascendencia, desde un punto de vista objetivo, como para provocar en la persona afectada una fuerte presión psíquica y llevarla a modificar sus pautas de actuación.

En cuanto a las reglas de penalidad, deben solventarse algunos desajustes que se advierten en los tipos cualificados, especialmente cuando la conducta se da entre personas recogidas en el artículo 173.2 CP y la víctima es especialmente vulnerable. En este caso la pena de prisión no coincide en los dos delitos agravados y, además, cuando la víctima pertenece al ámbito doméstico se permite imponer trabajos en beneficio de la comunidad, posibilidad que no se contempla respecto a las personas vulnerables. La respuesta habría de equipararse en ambos supuestos.

Finalmente, creo que debería suprimirse la norma concursal del apartado 3 del artículo 172 ter $\mathrm{CP}$, de manera que rigieran 
las disposiciones comunes tanto del concurso de delitos como de leyes. De este modo cuando los actos de acoso fueran constitutivos de otro delito, se aplicarían las reglas del concurso de normas, si el bien jurídico afectado coincide, al menos parcialmente, como en las amenazas. En cambio, regirían las del concurso de delitos si el objeto de tutela es distinto, pudiendo recurrir el juzgador a las del concurso ideal sin tener que penar separadamente las infracciones. En todo caso, cada conducta se valorará una sola vez evitando infringir el principio ne bis in ídem.

\section{Bibliografía citada}

ACALE SÁNCHEZ, M.: "Aspectos penales del Pacto de Estado español contra la violencia de género de 2017", en Diritto Penale Contemporaneo, 1/2018. (Disponible en https://www.penalecontemporaneo.it/d/5789-aspectospenales-del-pacto-de-estado-espaol-contra-la-violenciade-genero-de-2017).

ALONSO DE ESCAMILLA, A.: "El delito de stalking como nueva forma de acoso. Cyberstalking y nuevas realidades", en La Ley Penal, $\mathrm{n}^{\mathrm{o}}$ 105, noviembre-diciembre, 2013.

BAUCELLS LLADÓS, J.: "La irreflexiva criminalización del hostigamiento en el proyecto de Código penal", en Revista General de Derecho Penal, no 21, 2014.

BRAGE CENDÁN, S.B.: "La violencia machista: análisis del conflicto", en Estudios Penales y Criminológicos, vol. XXXII, 2012.

BUENO DE MATA, F.: "E-Violencia de género: tratamiento procesal de la violencia de género a través de la red", en Práctica de Tribunales, $\mathrm{n}^{\circ}$ 101, marzo-abril 2017.

CARPIO BRIZ, D., en CORCOY BIDASOLO, M./MIR PUIG, S. (Dir.): Comentarios al Código penal, Tirant lo Blanch, Valencia, 2015.

COBO DEL ROSAL, M./VIVES ANTÓN, T.S.: Derecho penal. Parte general, $5^{\mathrm{a}}$ edición, Tirant lo Blanch, Valencia, 1999. 
CONZELMANN, Y.: "Stalking ist keine Privatsache", Legal Tribune on Line, de 20 de febrero de 2017. (Disponible en https://www.lto.de/recht/hintergruende/h/238-stgbneufassung-stalking-gefaehrdungsdelikt-privatsacheschwachstellen/).

CUERDA ARNAU, M.L., en GONZÁLEZ CUSSAC, J.L. (Coord.): Derecho penal. Parte especial, $5^{\text {a }}$ edición, Tirant lo Blanch, Valencia, 2016.

DE LA CUESTA ARZAMENDI, J.L./MAYORDOMO RODRIGO, V.: "Acoso y Derecho penal", en Eguzkilore, no 25, 2011.

DELGADO MARTÍN, J.: "La violencia de género en redes sociales y mediante instrumentos tecnológicos de comunicación", en Cuadernos Digitales de Formación, no 4, 2016.

EISELE, J., en SCHÖNKE, A./SCHRÖDER, H.: Strafgesetzbuch: Kommentar, 29 Auflage, C.H.Beck, München, 2014.

GALDEANO SANTAMARÍA, A.: “Acoso - stalking: Art. 172 ter", en ÁLVAREZ GARCÍA, F.J. (Dir.)/DOPICO GÓMEZ-ALLER, J. (Coord.): Estudio crítico sobre el anteproyecto de reforma del Código penal de 2012, Tirant lo Blanch, Valencia, 2013.

GOIKOECHEA MARTÍN, L. A.: "Derecho de familia y Derecho penal. Novedades del Código penal en virtud de la Ley Orgánica 1/2015 y jurisprudencia penal”, en Cuadernos Digitales de Formación, no 39, 2016.

GÓMEZ RIVERO, M.C.: "El Derecho penal ante las conductas de acoso persecutorio", en MARTÍNEZ GONZÁLEZ, M.I.: El acoso: tratamiento penal y procesal, Tirant lo Blanch, Valencia, 2011.

KINDHÄUSER, U.: Strafgesetzbuch. Lehr- und Praxiskommentar, 5 Auflage, Nomos, Bade-Baden, 2013.

KRACK, R./KISCHE, S.: "Fortgeschrittenenhausarbeit - Strafrecht: Nachstellung mit unverhofften Folgen", en ZJS, 2010. (Disponible en http://www.zjs-online.com/dat/artikel/2010_6_398.pdf). 
KRÜGER, M.: "Stalking in allen Instanzen - Kritische Bestandsaufnahme erster Entscheidungen zu $\S 238$ StGB", en $N S t Z, \mathrm{n}^{\circ} 10,2010$.

KUBICIEL, M./BORUTTA, N.: "Strafgrund und Ausgestaltung des Tatbestandes der Nachstellung", en KriPoZ, n 3, 2016.

KÜHL, K.: Strafgesetzbuch: Kommentar, 27 Auflage, C.H.Beck, München, 2011.

LAMARCA PÉREZ, C., en LAMARCA PÉREZ, C (Coord.): Delitos. La parte especial del Derecho penal, Dykinson, Madrid, 2017.

MAGRO SERVET, V.: "Reforma del Código penal afectante a la violencia de género", en Diario La Ley, nº 8539, 14 de mayo de 2015.

- $\quad$ "El delito de stalking o acoso en la violencia de género en la reforma del Código penal", en Cuadernos Digitales de Formación, n $^{\circ}$ 56, 2016.

MARTÍNEZ MUÑOZ, C.J.: "El «nuevo» delito de acoso del artículo 172 ter", en Diario La Ley, n 9006, 22 de junio de 2017.

MATALLÍN EVANGELIO, A.: "Delito de acoso (Artículo 172 ter)", en GONZÁLEZ CUSSAC, J.L. (Dir.)/GÓRRIZ ROYO, E./MATALLÍN EVANGELIO, A. (Coord.): Comentarios a la reforma del Código penal de 2015, $2^{\mathrm{a}}$ edición, Tirant lo Blanch, Valencia, 2015.

- “Acoso -stalking-: Art. 172 ter", en ÁLVAREZ GARCÍA, F.J. (Dir.)/DOPICO GÓMEZ-ALLER, J. (Coord.): Estudio crítico sobre el anteproyecto de reforma del Código penal de 2012, Tirant lo Blanch, Valencia, 2013.

MEYER, F.: "Strafbarkeit und Strafwürdigkeit von «Stalking» im deutschen Recht", en ZStW, no 115, 2003.

MIRÓ LLINARES, F.: "La ciberdelincuencia", en Cuadernos Digitales de Formación, no $46,2015$.

MÜLLER, H.E.: "Reform des $\S 238$ StGB - "Stalking", eine gute Idee?", beck-community, de 17 de febrero de 2016. (Disponible en https://community.beck.de/2016/02/17/ reform-des-238-stgb-stalking-eine-gute-idee). 
MUÑOZ CONDE, F.: "Diversas modalidades de acoso punible en el Código penal", en MARTÍNEZ GONZÁLEZ, M.I.: El acoso: tratamiento penal y procesal, Tirant lo Blanch, Valencia, 2011.

- Derecho penal. Parte especial, Tirant lo Blanch, Valencia, 2017.

ORTS BERENGUER, E./GONZÁLEZ CUSSAC, J.L.: Compendio de Derecho penal. Parte general, $7^{\text {a }}$ edición, Tirant lo Blanch, Valencia, 2017.

PALMA HERRERA en MORILLAS CUEVA, L. (Dir.): Estudios sobre el Código penal reformado, Dykinson, Madrid, 2015.

PERAMATO MARTÍN, T.: "Los nuevos tipos penales de violencia de género", en Cuadernos Digitales de Formación, $\mathrm{n}^{\circ} 18,2017$.

PUJOLS PÉREZ, S.: “Aplicación del delito de quebrantamiento de condena como respuesta penal a las conductas de stalking: problemática suscitada", en Revista General de Derecho Penal, $\mathrm{n}^{\circ}$ 23, 2015.

QUERALT JIMÉNEZ, J.J.: Derecho penal español. Parte especial, $7^{\mathrm{a}}$ edición, Tirant lo Blanch, Valencia, 2015.

RODRÍGUEZ LAÍN, J.L.: "El nuevo delito de ciberacoso: aspectos sustantivos y procesales", en Cuadernos Digitales de Formación, n⿳亠 2, 2016.

SERRANO GÓMEZ, A., en SERRANO GÓMEZ, A./SERRANO MAÍLLO, A./SERRANO TÁRRAGA, M.D./VÁZQUEZ GONZÁLEZ, C.: Curso de Derecho penal. Parte especial, $4^{\text {a }}$ edición, Dykinson, Madrid, 2017.

SCHLUCKEBIER, W., en SATGER, H./SCHMITT, B./WIDMAIER, G.: Strafgesetzbuch Kommentar, 1 Auflage, Carl Heymanns, München, 2009.

TAPIA BALLESTEROS, P.: El nuevo delito de acoso o stalking, Bosch, Barcelona, 2016.

VALERIUS, B.: "Stalking: Der Neue Straftatbestand der Nachstellung in $\S 238$ StGB", en $J u S, n^{\circ} 4,2007$.

VELASCO NÚÑEZ, E.: "Los delitos informáticos", en Cuadernos Digitales de Formación, n 33, 2015. 
VILLACAMPA ESTIARTE, C.: Stalking y Derecho penal, Iustel Madrid, 2009.

- "La introducción del delito de "atti persecutori" en el Código penal italiano", en InDret, no 3, 2009.

- $\quad$ "La respuesta jurídico-penal frente al stalking en España: presente y futuro", en ReCrim, 2010.

"El proyectado delito de acecho: incriminación del stalking en Derecho penal español", en Cuadernos de Política Criminal, $\mathrm{n}^{\circ}$ 109, 2013.

- en QUINTERO OLIVARES, G. (Dir.): Comentario a la reforma de 2015, Aranzadi, Pamplona, 2015.

- en QUINTERO OLIVARES, G. (Dir.)/MORALES PRATS, F. (Coord.): Comentarios al Código penal español, Tomo I, Aranzadi, Pamplona, 2016.

- "El delito de stalking", en LAFONT NICUESA, L. (Coord.): Los delitos de acoso moral: mobbing, acoso inmobiliario, bulling, stalking, escraces y ciberacoso, Tirant lo Blanch, Valencia, 2017. 